Article

\title{
Energy and Exergy (2E) Analysis of an Optimized Solar Field of Linear Fresnel Reflectors for a Conceptual Direct Steam Generation Power Plant
}

\author{
Eduardo González-Mora (D) and Ma. Dolores Durán-García * \\ Ingeniería en Sistemas Energéticos Sustentables, Facultad de Ingeniería, Universidad Autónoma del Estado de \\ México, Cerro de Coatepec S/N, Toluca 50110, Mexico; egonzalezmo@uaemex.mx \\ * Correspondence: mddurang@uaemex.mx
}

Citation: González-Mora, E.; Durán-García, M.D. Energy and Exergy (2E) Analysis of an Optimized Solar Field of Linear Fresnel Reflectors for a Conceptual Direct Steam Generation Power Plant. Energies 2021, 14, 4234. https:// doi.org/10.3390/en14144234

Academic Editor: Loreto Valenzuela

Received: 1 June 2021

Accepted: 7 July 2021

Published: 13 July 2021

Publisher's Note: MDPI stays neutral with regard to jurisdictional claims in published maps and institutional affiliations.

Copyright: (c) 2021 by the authors. Licensee MDPI, Basel, Switzerland. This article is an open access article distributed under the terms and conditions of the Creative Commons Attribution (CC BY) license (https:/ / creativecommons.org/licenses/by/ $4.0 /)$.

\begin{abstract}
Direct steam generation is a promising alternative to conventional heat transfer fluids for solar thermal power plants using linear concentrators because water and steam do not have thermal and chemical stability problems. The novelty of this study, an energy and exergy (2E) analysis, was that it was performed on several configurations of a conceptual direct steam generation solar power plant with optimized Fresnel reflectors in Agua Prieta, Mexico coupled with a regenerative steam Rankine power cycle to quantify their efficiency and establish a reference for future implementation of this technology in concentrated solar power plants in Mexico. The thermal model was assumed to be a 1D steady-state flow and validated against results in the literature. It was then applied directly to a case study to determine the size of the solar field. The design point was the lowest solar irradiance day, and evaluating the solar multiple with the highest solar irradiance, taking care not to oversize the solar field, as suggested for solar plants without energy storage. Comparing the performance of the optimized Fresnel field against the FRESDEMO field of Plataforma Solar de Almería, a considerable decrease in the length of the loop has been demonstrated with a low reduction in thermal efficiency.
\end{abstract}

Keywords: linear Fresnel reflector; direct steam generation; energy; exergy; efficiency

\section{Introduction}

In recent years, the towering environmental problems faced around the world have increased the urgency to incorporate technologies for harvesting renewable resources to satisfy energy demand. In 2018, the global energy demand was estimated to be $556 \mathrm{E}$, of which 88.3 EJ was for generating electricity [1]. As an alternative to fossil fuels, solar technologies such as concentrated solar power (CSP) have been added to the energy mix. CSP uses different mirror configurations to concentrate the incident solar radiation onto a smaller area called a receiver, where high heat is supplied to a heat transfer fluid (HTF) that is used to drive a heat engine and generate electric power.

Any attempts to optimize a process to increase its efficiency will directly influence the system's energy inputs and outputs. The authors' present work is focused on optimizing the configuration of the FRESDEMO field (demonstration module of a Linear Fresnel Collector) developed in the Plataforma Solar de Almeria (PSA), which is the reference field that uses linear Fresnel reflectors (LFRs) for direct steam generation (DSG) [2]. The considered optimization maintains similar parameters to the FRESDEMO field, which allows the amount of energy on the receiver to be increased [3].

DSG was introduced in the 1990s as an alternative to parabolic through collectors (PTC) driven steam Rankine cycles using an HTF, to reduce the system's capital and maintenance costs $[4,5]$, and several studies were performed to sort the problems associated with bending [6,7]. However, the absence of a storage system or an intermediate HTF results in adapting the intermittent nature of the solar energy limiting the controllability and stability of the whole installation, as demonstrated in the early 2000s [8,9]. 
Even though DSG has begun to gain popularity because of the reduced costs of the associated equipment, currently there are few commercial plants using DSG technology, in contrast to one of the objectives laid out by the International Energy Agency (IEA), which predicted that the introduction of DSG at the commercial level would occur by the late 2010s [10]. To date, there are about 110 operational plants [11], with an installed capacity of $6289 \mathrm{MW}$ [12]. Of the total installed, just over $522 \mathrm{MW}$ are obtained through DSG, of which the power towers make the greatest contribution with $90.9 \%$, LFRs contribute $7.7 \%$, and only the $5 \mathrm{MW}$ Thai Solar Energy 1 plant uses PTC [11]. A brief review of the coupling of DSG and CSP is shown in Table 1.

Table 1. Solar thermal plants operating with DSG Rankine cycle [11].

\begin{tabular}{|c|c|c|c|c|}
\hline Name & Technology & $\begin{array}{l}\text { Capacity } \\
\text { (MW) }\end{array}$ & Storage/Back Up & Status \\
\hline \multicolumn{5}{|l|}{ Greenway CSP } \\
\hline $\begin{array}{l}\text { Mersin } \\
\text { (Turkey) }\end{array}$ & Power tower & 1 & Molten salt tank & Non-operational \\
\hline $\begin{array}{l}\text { Puerto Errado } 1 \\
\text { (Spain) }\end{array}$ & LFR & 1.4 & $\begin{array}{l}\text { Single thermocline } \\
\text { tank }\end{array}$ & Operational \\
\hline $\begin{array}{l}\text { Sundrop } \\
\text { (Australia) }\end{array}$ & Power tower & 1.5 & No storage & Operational \\
\hline $\begin{array}{l}\text { Lake Cargelligo } \\
\text { (Australia) }\end{array}$ & Power tower & 3 & $\begin{array}{c}\text { Graphite thermal } \\
\text { storage }\end{array}$ & Non-operational \\
\hline \multicolumn{5}{|l|}{ Liddell Power } \\
\hline $\begin{array}{c}\text { Station } \\
\text { (Australia) }\end{array}$ & LFR & 3 & No storage & Non-operational \\
\hline $\begin{array}{l}\text { Thai solar one } \\
\text { (Thailand) }\end{array}$ & PTC & 5 & No storage & Operational \\
\hline $\begin{array}{c}\text { Kimberlina } \\
\text { (USA) }\end{array}$ & LFR & 5 & No storage & Non-operational \\
\hline $\begin{array}{c}\text { Sierra SunTower } \\
\text { (USA) }\end{array}$ & Power tower & 5 & No storage & Non-operational \\
\hline $\begin{array}{c}\text { eLLO } \\
\text { (France) }\end{array}$ & LFR & 9 & Steam drum & Operational \\
\hline $\begin{array}{c}\text { PS10 } \\
\text { (Spain) }\end{array}$ & Power tower & 11 & Heat storage & Operational \\
\hline $\begin{array}{l}\text { Dadri ISCC Plant } \\
\text { (India) }\end{array}$ & LFR & 14 & Not specified & $\begin{array}{c}\text { Under } \\
\text { construction }\end{array}$ \\
\hline $\begin{array}{c}\text { PS20 } \\
\text { (Spain) }\end{array}$ & Power tower & 20 & Heat storage & Operational \\
\hline $\begin{array}{l}\text { Puerto Errado } \\
\text { (Spain) }\end{array}$ & LFR & 30 & $\begin{array}{l}\text { Single thermocline } \\
\text { tank }\end{array}$ & Operational \\
\hline $\begin{array}{l}\text { Khi Solar One } \\
\text { (Spain) }\end{array}$ & Power Tower & 50 & Steam drum & Operational \\
\hline $\begin{array}{l}\text { Shangyi Tower } \\
\text { (China) }\end{array}$ & Power Tower & 50 & 2 molten salt tanks & $\begin{array}{c}\text { Under } \\
\text { development }\end{array}$ \\
\hline $\begin{array}{c}\text { Zhangbei } \\
\text { (China) }\end{array}$ & LFR & 50 & $\begin{array}{l}\text { Solid-state } \\
\text { formulated } \\
\text { concrete }\end{array}$ & Non-operational \\
\hline $\begin{array}{c}\text { Zhangiiakou } \\
\text { (China) }\end{array}$ & LFR & 50 & $\begin{array}{l}\text { Solid-state } \\
\text { formulated } \\
\text { concrete }\end{array}$ & $\begin{array}{c}\text { Under } \\
\text { development }\end{array}$ \\
\hline $\begin{array}{c}\text { Huanghe Qinghai } \\
\text { Delingha } \\
\text { (China) }\end{array}$ & Power Tower & 135 & 2 molten salt tanks & Non-operational \\
\hline $\begin{array}{l}\text { Ivanpah } \\
\text { (USA) }\end{array}$ & Power Tower & 392 & No storage & Operational \\
\hline
\end{tabular}

While both DSG and LFRs have high implementation potential, their development has not yet reached the necessary maturity to make them commercially viable as PTCs 
using thermal oils as HTF. For this reason, an energy and exergy analysis (2E) of an optimized Fresnel field with DSG coupled to different configurations of Rankine cycles is needed to establish a reference for its future implementation in Mexico. The 2E analysis is necessary for objectively comparing any systems. Although the energy analysis is suitable for determining the efficiency of a system, it does not give information on the quality and locations of imperfections in the system. Exergy analysis serves as a tool for identifying the magnitude and location of irreversibilities in thermal systems [13-16].

One of the most representative thermal analyses on CSP with DSG was by Montes Pita [4], who considered different solar field configurations for varying operating conditions and materials. This work gives a starting point for the thermal analysis of LFRs for DSG. Giostri et al. [17] compared the thermal performance of two solar plants using thermal oil as the HTF with PTCs and with LFRs. Although they also simulated DSG with LFRs, this was not compared with the others. They proved that a solar field using DSG performs better than one using oil under the same operating conditions. Hirsch and Khenissi [18] demonstrated that superheating is a viable alternative at moderate temperatures $\left(\leq 450{ }^{\circ} \mathrm{C}\right)$ and pressures lower than 14 bar in solar plants with 50 MW DSG. Although they did not explain what type of concentrator they used (PTC or LFR), the large number of parameters that were considered in their simulations indicates that their work can be used as a reference for operating conditions.

Sun et al. [19] numerically simulated a solar plant with PTCs in recirculation and performed a 2E analysis. However, their model does not specify the power output of the solar plant. Hakkarainen et al. [20] compared two configurations for DSG using PTCs and LFRs. They showed that the LFR field needs to be almost twice the size of the PTC field to achieve the same thermal power output for the solar plant, although they did note that LFRs provide better controllability than PTCs over DSG.

Although different groups have performed thermal analyses on LFR solar fields, the vast majority performed a $2 \mathrm{E}$ analysis on a single configuration or single power range, which limited the comparison of results to demonstrating the technical feasibility of using LFRs with DSG. Thus, the objective of the present study intends to describe a conceptual direct steam generation solar power plant for Agua Prieta, Mexico with different configurations for the solar field and a Rankine cycle, and compare the results with the FRESDEMO field.

A starting point was established by determining the configurations of $10 \mathrm{MW}$ regenerative Rankine cycles and quantifying the required thermal power output of the optimized solar field. A thermo-hydraulic model was developed to consider different aspects of establishing the heat fluxes and surface temperatures of the elements involved in the receiver based on the methodology proposed by Adiutori [21], where the use of the heat transfer coefficient is omitted to avoid the iterative process involved in its determination. This allowed a direct solution to be obtained for all variables involved. The developed model is versatile and can be used to study the behavior of the system with different working fluids simply by changing the thermodynamic properties of the working fluid. Finally, configurations of the solar field were established to set the field dimensions for meeting the operating requirements of the proposed Rankine cycles. The solar multiple was determined for the conditions with the highest and lowest insolation.

\section{Characterization of Thermodynamic Cycles}

Even though the objective of this work was a 2E analysis of the LFR system, characterizing the thermodynamic cycle will allow the theoretical efficiency of the Rankine cycle configurations to be determined. Maximizing the work output (i.e., improving the thermal efficiency) depends on the available energy supplied as heat in the steam generator, the output of the system (turbine work), and the work required to operate the pumps that are part of the cycle. While increasing the work output, the entropy generation in the cycle is minimized as stated by the Guoy-Stodola theorem [22]. Thus, when considering the net power output of the system, the amount of heat needed in the steam generator can be 
quantified to define the size of the solar field, as described in Section 3. A Rankine cycle can have a reheating or regeneration configuration. For solar-only power plants, regeneration is preferred [23]. Under this premise, a regenerative steam Rankine cycle was the configuration used in the present study. The goal of the thermodynamic characterization was to establish the thermodynamic state of each flow of mass, energy, entropy, and exergy involved in the cycle to quantify the useful power output of the system and identify the irreversibilities in the power cycle [24,25].

\subsection{Operating Parameters of the Regenerative Rankine Cycle}

An important consideration for the analysis of power systems is determining the design points (i.e., boundary conditions), which are the settings under which the power block will be operating under nominal conditions. The following design points were identified for a power plant similar to the FRESDEMO project [15]: net power output of $10 \mathrm{MW}$, pressure of $100 \mathrm{bar}$, and temperature of $400{ }^{\circ} \mathrm{C}(673.15 \mathrm{~K})$ of steam at the turbine inlet, and pressure of 0.08 bar at the turbine outlet. The turbine, which is the most important component of a thermoelectric plant, must be selected according to these design points. Considering the steam conditions and net power output of the system, a Siemens SST200 turbine with a nominal isentropic efficiency of $80 \%$ [26] was selected because it can adequately handle the proposed power ranges and its characteristics are adapted to the standards of the simulations [27].

The number and location of extraction points for preheating the feed water in a given plant is a significant consideration. Although using many regenerators results in higher exergy efficiency, this leads to overly complicated operations and has a substantial impact on the installation costs [28]. The extraction of steam in the turbine reduces the nominal isentropic efficiency [29]. In the present work, two configurations were considered for the steam Rankine cycles: two and three steam extractions. Since the only given data were the pressures at the inlet and outlet of the turbine, the location of the extraction points in the system (extraction pressures) was optimized to maximize the efficiency of the power cycle, according to the criterion established in the literature to minimize the exergy destruction $[28,30]$. This made it possible to quantify the thermal energy necessary for the operation of the power cycles.

\subsection{Analyzed Cycles}

\subsubsection{Regenerative Cycle with two Steam Extractions}

Figure 1a shows a schematic of the configuration of the steam Rankine cycle. To define each thermodynamic state, the steam extraction pressure was determined in a sensitivity analysis. This sensitivity analysis was performed comparing the variation of the exergy efficiency in the power block (excluding the solar field) for different values of the extraction pressure. As a result, power block exergy efficiency was maximized around 8 bar. This pressure was used to characterize the cycle, as presented in Table 2 and the T-s diagram of Figure $1 \mathrm{~b}$. A mass flux of $12.81 \mathrm{~kg} / \mathrm{s}$ is required to achieve a net power output of $10 \mathrm{MW}$. The obtained results indicated an energy efficiency of 0.3652 (i.e., $36.52 \%$ ) and exergy efficiency of 0.8247 (i.e., $82.47 \%$ ). 


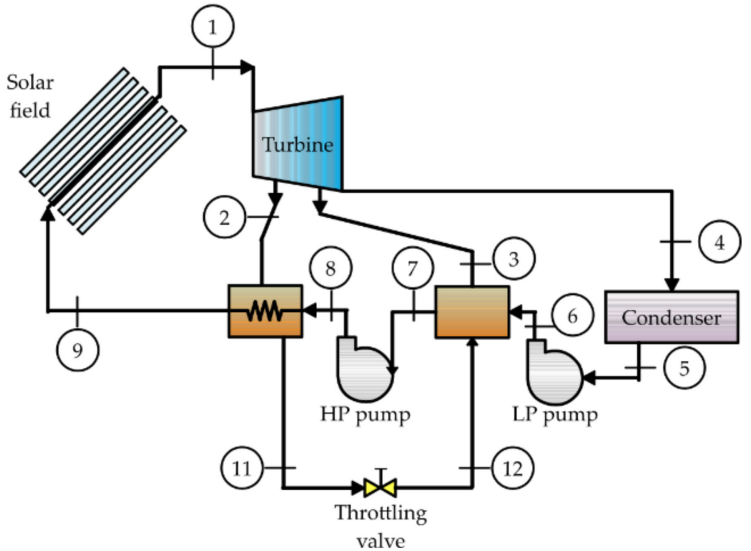

(a)

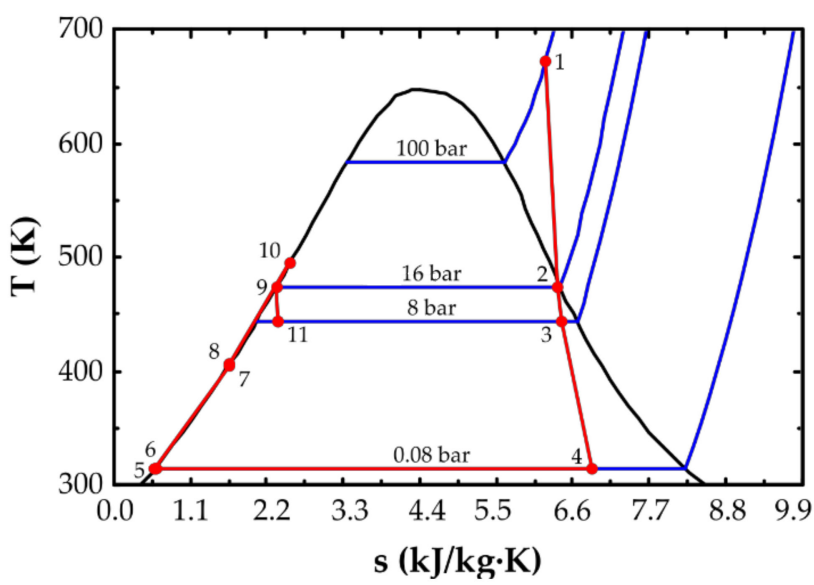

(b)

Figure 1. Regenerative Rankine cycle with two steam extractions: (a) Schematic diagram; (b) T-s diagram.

Table 2. Two steam extractions regenerative Rankine cycle thermodynamic characterization.

\begin{tabular}{ccccccc}
\hline State & $\mathbf{T}_{\mathbf{i}}(\mathbf{K})$ & $\mathbf{P}_{\mathbf{i}}(\mathbf{b a r})$ & $\mathbf{h}_{\mathbf{i}}(\mathbf{k J} / \mathbf{k g})$ & $\mathbf{s}_{\mathbf{i}}(\mathbf{k J} / \mathbf{k g} \mathbf{K})$ & $\mathbf{b}_{\mathbf{i}}(\mathbf{k J} / \mathbf{k g})$ & $\mathbf{x}_{\mathbf{i}}$ \\
\hline 1 & 673.2 & 100 & 3097.4580 & 6.2141 & 1249.2832 & superheatedsteam \\
2 & 474.5 & 16 & 2775.6092 & 6.3837 & 876.8784 & 0.9911 \\
3 & 443.6 & 8 & 2672.1738 & 6.4449 & 755.1900 & 0.9530 \\
4 & 314.7 & 0.08 & 2153.1660 & 6.8829 & 105.5952 & 0.8239 \\
5 & 314.7 & 0.08 & 173.8396 & 0.5925 & 1.7490 & 0 \\
6 & 314.7 & 8 & 174.9044 & 0.5933 & 2.5616 & liquid \\
7 & 404.6 & 8 & 552.4712 & 1.6497 & 65.1769 & 0 \\
8 & 406.3 & 100 & 566.3182 & 1.6582 & 76.4810 & liquid \\
9 & 496.1 & 100 & 959.3855 & 2.5312 & 209.2742 & liquid \\
10 & 474.5 & 16 & 858.4440 & 2.3435 & 164.3041 & 0 \\
11 & 443.6 & 8 & 858.4440 & 2.3858 & 160.6143 & 0.0672 \\
\hline
\end{tabular}

\subsubsection{Regenerative Cycle with Three Steam Extractions}

Figure 2a shows a schematic of the second configuration of the power cycle. Like the previous case, a sensitivity analysis was carried out to establish the extraction pressures that maximize the exergy efficiency of the power block. This maximization resulted in a pressure of 20 bar for the first extraction, 4 bar for the second extraction, and 2 bar for the last extraction. The thermodynamic states of the ith-flows are reported in Table 3 and the T-s diagram of Figure $2 b$. The results indicated an energy efficiency of 0.3706 (i.e., 37.06\%) and an exergy efficiency of 0.8661 (i.e., 86.61\%). A net power output of $10 \mathrm{MW}$ requires $13.26 \mathrm{~kg} / \mathrm{s}$ of water. 


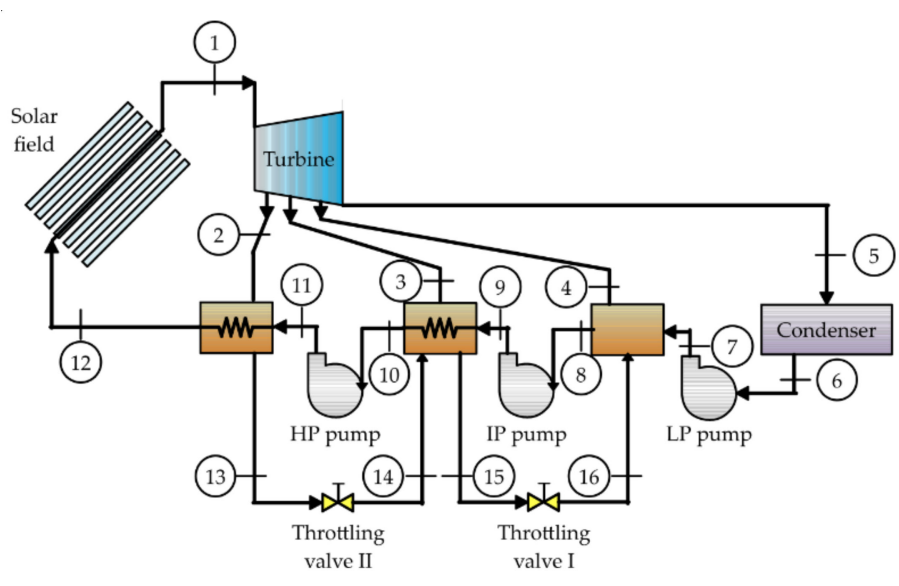

(a)

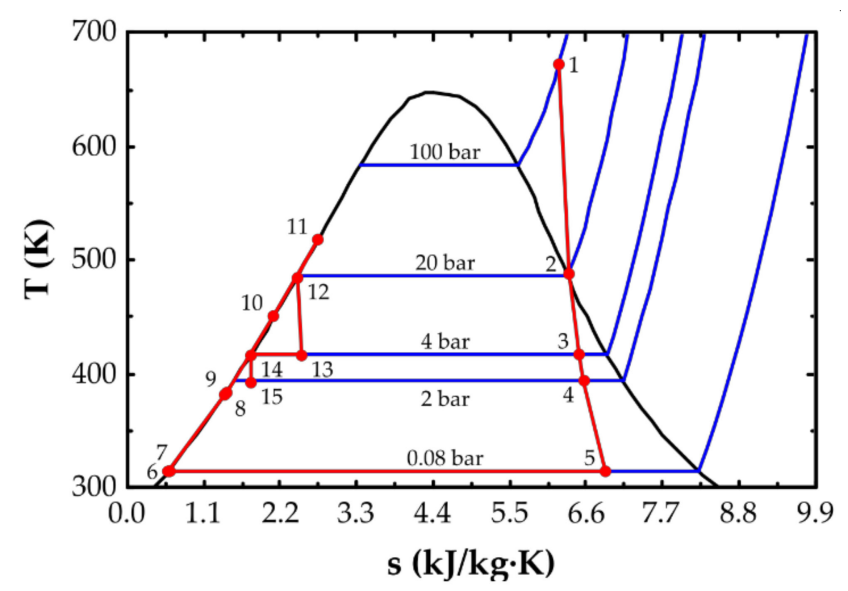

(b)

Figure 2. Regenerative Rankine cycle with three steam extractions: (a) Schematic diagram; (b) T-s diagram.

Table 3. Three steam extraction regenerative Rankine cycle thermodynamic characterization.

\begin{tabular}{ccccccc}
\hline State & $\mathbf{T}_{\mathbf{i}}(\mathbf{K})$ & $\left.\mathbf{P}_{\mathbf{i}} \mathbf{( b a r}\right)$ & $\mathbf{h}_{\mathbf{i}}(\mathbf{k J} / \mathbf{k g})$ & $\mathbf{s}_{\mathbf{i}}(\mathbf{k J} / \mathbf{k g} \mathbf{K})$ & $\mathbf{b}_{\mathbf{i}}(\mathbf{k J} / \mathbf{k g})$ & $\mathbf{x}_{\mathbf{i}}$ \\
\hline 1 & 673.2 & 100 & 3097.4580 & 6.2141 & 1249.2832 & $\begin{array}{c}\text { superheated } \\
\text { steam } \\
\text { superheated } \\
\text { steam }\end{array}$ \\
2 & 489.1 & 20 & 2809.6092 & 6.3622 & 917.2702 & 0.9242 \\
3 & 416.8 & 4 & 2576.3714 & 6.5075 & 640.7096 & 0.9003 \\
4 & 393.4 & 2 & 2486.6878 & 6.5688 & 532.7680 & 0.8217 \\
5 & 314.7 & 0.08 & 2147.8559 & 6.8660 & 105.3166 & 0 \\
6 & 314.7 & 0.08 & 173.8396 & 0.5925 & 1.7490 & liquid \\
7 & 314.7 & 2 & 174.0977 & 0.5927 & 1.9460 & 0 \\
8 & 382.1 & 2 & 456.7724 & 1.4067 & 41.9233 & liquid \\
9 & 383.6 & 100 & 470.5577 & 1.4157 & 53.0272 & liquid \\
10 & 451 & 100 & 758.2368 & 2.1063 & 134.8163 & liquid \\
11 & 518.4 & 100 & 1062.9448 & 2.7353 & 251.9609 & 0 \\
12 & 485.5 & 20 & 908.4743 & 2.4467 & 183.5490 & 0.1424 \\
13 & 416.8 & 4 & 908.4743 & 2.5055 & 166.0308 & 0 \\
14 & 416.8 & 4 & 604.6573 & 1.7765 & 79.5653 & 0.0454 \\
15 & 393.4 & 2 & 604.6573 & 1.7843 & 77.2359 & \\
\hline
\end{tabular}

\section{Solar Field: Linear Fresnel Reflector}

Although the optical description of LFRs is simple, many parameters need to be considered for the design of LFR systems. However, very little data are available to describe an LFR field [31]. Based on the descriptions for different LFR designs, the FRESDEMO field located at Plataforma Solar de Almería in Spain was selected as a starting point.

The parameters of the FRESDEMO field were taken as a reference to perform an optical optimization for the city of Agua Prieta, Sonora, in northwest México. The optimization of the intercept factor resulted in an increase in the receiver height from $8 \mathrm{~m}$ to $15 \mathrm{~m}$, and the compound parabolic concentrator (CPC) of the second stage of the cavity was modified to maintain the opening area of the receiver [3]. As a result of the performed optimization, the average optical concentration increases from 61.64 to 79.31 . This increase will lead to a significant reduction in the loop length of the solar field.

Table 4 describes the parameters of the optimized field. Figure 3 shows the incident angle modifiers (IAMs) that were determined for the optimized LFR; these represent the changes in optical efficiency for angles of incidence other than perpendicular. Figure 4 shows the relation between the variation in the average optical concentrator on the plane of the absorber and the IAMs. 
Table 4. Description of the optically optimized LFR field for Agua Prieta, Sonora [3].

\begin{tabular}{cc}
\hline Parameter & Value \\
\hline Number of primary mirrors & 25 \\
Solar field width $(\mathrm{m})$ & 21 \\
Total length of the primary mirrors $(\mathrm{m})$ & 100 \\
Width of the primary mirrors $(\mathrm{m})$ & 0.6 \\
Filling factor & 0.7143 \\
Receiver height $(\mathrm{m})$ & 15 \\
Receiver width $(\mathrm{m})$ & 0.5 \\
Absorber tube outer diameter $(\mathrm{m})$ & 0.14 \\
Absorber tube inner diameter $(\mathrm{m})$ & 0.125 \\
Semi-angle acceptance of the CPC $\left(^{\circ}\right)$ & 66.30 \\
Intercept factor & 0.7231 \\
Geometric concentration of the CPC & 1.1368 \\
Geometric concentration of the entire field & 34.105 \\
Number of supports per module & 17 \\
\hline
\end{tabular}

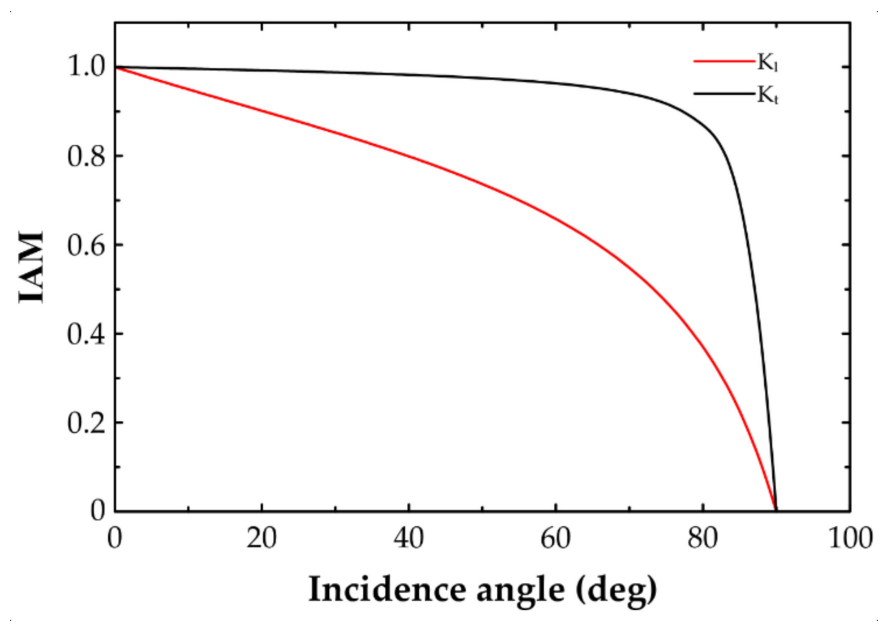

Figure 3. Incidence angle modifiers for the longitudinal $\left(\mathrm{K}_{\mathrm{l}}\right)$ and transverse $\left(\mathrm{K}_{\mathrm{t}}\right)$ directions [3].

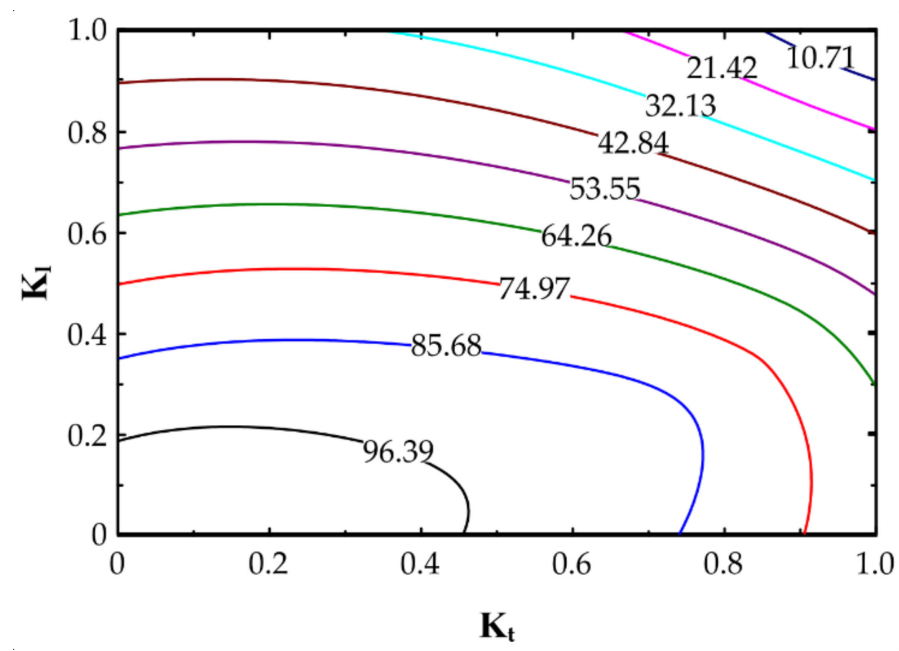

Figure 4. Average optical concentration on the receiver plane [3].

\section{Thermo-Hydraulic Model Description and Validation}

The thermo-hydraulic model is adapted as described by other researchers $[15,32]$ to the Adiutori methodology [21], as described in previous work [33], and discussed below. Figure 5a shows a schematic of the heat fluxes involved in the surfaces of the receiver. Figure $5 \mathrm{~b}$ shows the interaction of the involved fluxes in a thermal resistance 
model equivalent to the heat transfer in the receiver cavity. All the terms in Figure 5 are defined in Table 5.

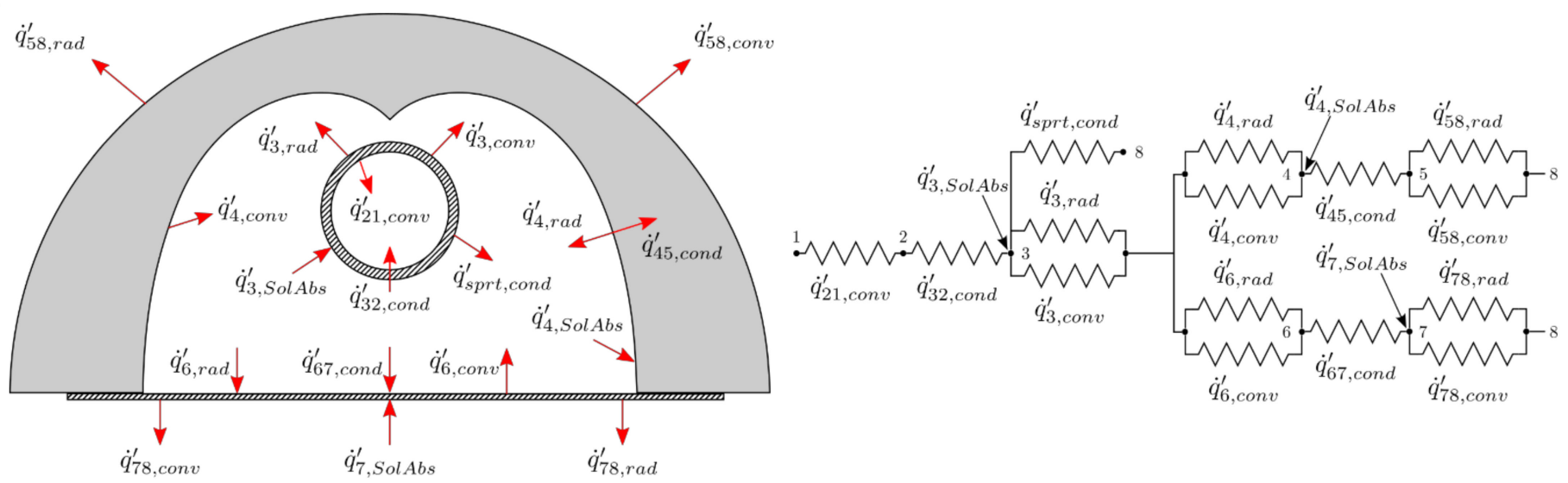

(a)

(b)

Figure 5. Heat transfer model in the cavity in the receiver: (a) Cross section of a single tube Fresnel receiver; (b) Thermal resistance model for single tube Fresnel receiver.

Table 5. Definition of heat fluxes in the cavity.

\begin{tabular}{|c|c|c|c|}
\hline \multirow{2}{*}{ Heat Flux (W/m) } & \multirow{2}{*}{ Heat Transfer Mode } & \multicolumn{2}{|c|}{ Heat Transfer Path } \\
\hline & & from & to \\
\hline$\dot{q}_{21, \text { conv }}^{\prime}$ & Convection & Inner absorber tube & Heat transfer fluid \\
\hline$\dot{q}_{32, \text { cond }}^{\prime}$ & Conduction & Outer absorber tube & Inner absorber tube \\
\hline$\dot{q}_{s p t, \text { cond }}^{\prime}$ & Conduction & Outer absorber tube & HCE supports \\
\hline$\dot{q}_{3, \text { Sol Abs }}^{\prime}$ & $\begin{array}{l}\text { Absorption of solar } \\
\text { radiation }\end{array}$ & $\begin{array}{l}\text { Incident solar } \\
\text { radiation }\end{array}$ & Outer absorber tube \\
\hline$\dot{q}_{3 \operatorname{rad}}^{\prime}$ & Radiation & Outer absorber tube & Cavity \\
\hline$\dot{q}_{3 \operatorname{conv}}^{\prime}$ & Convection & Outer absorber tube & Cavity \\
\hline$\dot{q}_{4, \mathrm{rad}}$ & Radiation & CPC surface & Cavity \\
\hline$\dot{q}_{4, \text { conv }}^{\prime}$ & Convection & CPC surface & Cavity \\
\hline$\dot{q}_{4, S o l A b s}^{\prime}$ & $\begin{array}{l}\text { Absorption of solar } \\
\text { radiation }\end{array}$ & $\begin{array}{l}\text { Incident solar } \\
\text { radiation }\end{array}$ & $\mathrm{CPC}$ surface \\
\hline$\dot{q}_{45 \text { cond }}^{\prime}$ & Conduction & CPC surface & Insulation \\
\hline$\dot{q}_{58, \text { rad }}^{\prime}$ & Radiation & Insulation & Environment \\
\hline$\dot{q}_{58, \text { conv }}^{\prime}$ & Convection & Insulation & Environment \\
\hline$\dot{q}_{6, \text { rad }}^{\prime \prime}$ & Radiation & Inner Pyrex surface & Cavity \\
\hline$\dot{q}_{6, \text { conv }}^{\prime}$ & Convection & Inner Pyrex surface & Cavity \\
\hline$\dot{q}_{67, \text { cond }}^{\prime}$ & Conduction & Inner Pyrex surface & Outer Pyrex surface \\
\hline$\dot{q}_{7, \text { Sol Abs }}^{\prime}$ & $\begin{array}{l}\text { Absorption of solar } \\
\text { radiation }\end{array}$ & $\begin{array}{l}\text { Incident solar } \\
\text { radiation }\end{array}$ & Outer Pyrex surface \\
\hline$\dot{q}_{78, \mathrm{rad}}^{\prime}$ & Radiation & Outer Pyrex surface & Environment \\
\hline$\dot{q}_{78, \text { conv }}^{\prime}$ & Convection & Outer Pyrex surface & Environment \\
\hline
\end{tabular}

The thermal energy equations were determined by balancing the energy at each surface of the cross-section of the receiver cavity according to the resistance thermal model in Figure $5 b$ and are given below by Equations (1)-(6). Equation (7) was added to balance the change in enthalpy of the HTF as it flows through the absorber tube.

$$
\dot{q}_{21, \text { conv }}^{\prime}=\dot{q}_{32, \text { cond }}^{\prime}
$$




$$
\begin{gathered}
\dot{q}_{3, \text { Sol Abs }}^{\prime}=\dot{q}_{32, \text { cond }}^{\prime}+\dot{q}_{3, \mathrm{rad}}^{\prime}+\dot{q}_{3, \mathrm{conv}}^{\prime}+\dot{q}_{\text {spt,cond }}^{\prime} \\
\dot{q}_{45, \mathrm{cond}}^{\prime}=\dot{q}_{4, \text { Sol Abs }}^{\prime}+\dot{q}_{4, \mathrm{rad}}^{\prime}+\dot{q}_{4, \mathrm{conv} v^{\prime}}^{\prime} \\
\dot{q}_{45, \mathrm{cond}}^{\prime}=\dot{q}_{58, \mathrm{rad}}^{\prime}+\dot{q}_{58, \mathrm{conv}}^{\prime} \\
\dot{q}_{67, \mathrm{cond}}^{\prime}=\dot{q}_{6, \mathrm{rad}}^{\prime}+\dot{q}_{6, \mathrm{conv}}^{\prime} \\
\dot{q}_{7, \text { Sol Abs }}^{\prime}+\dot{q}_{67, \mathrm{cond}}^{\prime}=\dot{q}_{78, \mathrm{rad}}^{\prime}+\dot{q}_{78, \mathrm{conv}}^{\prime} \\
\dot{q}_{21, \mathrm{conv}}^{\prime}=\frac{\dot{m}}{L_{H C E}}\left(h_{1 \mathrm{out}}-h_{1 \mathrm{in}}\right),
\end{gathered}
$$

\subsection{Solar Absorption}

Although the solar radiation fluxes in opaque (such as the absorber) and semitransparent materials (such as the glass cover) are volumetric phenomena, most of the absorption in the absorber occurs very close to the surface (approximately $6 \AA$ ) [34,35], and although solar absorption occurs throughout the thickness of the glass envelope, the absorptivity is relatively small (even for polarized radiation incident at a large angle [36]). These terms can be calculated as:

$$
\begin{gathered}
\dot{q}_{3, \text { SolAbs }}^{\prime}=\tau_{67} \rho_{4} \alpha_{23} \dot{q}_{i n c, r e c^{\prime}}^{\prime} \\
\dot{q}_{4, \text { Sol Abs }}^{\prime}=\tau_{67} \alpha_{45} \dot{q}_{\text {inc,rec }}^{\prime} \\
\dot{q}_{7, \text { Sol Abs }}^{\prime}=\alpha_{67} \dot{q}_{i n c, r e c^{\prime}}^{\prime}
\end{gathered}
$$

where $\tau_{67}=0.967, \rho_{4}=0.97, \alpha_{23}=0.94, \alpha_{45}=0.03$, and $\alpha_{67}=0.035$. The incident solar radiation into the receiver $\left(\dot{q}_{i n c, r e c}^{\prime}\right)$ takes into account the reflectivity of the primary mirrors and the IAM. The optical parameters are: $\tau$ for the transmittance, $\alpha$ for absorptivity, and $\rho$ for reflectivity of each surface as defined in Table 5 .

\subsection{Convective Heat Fluxes}

To calculate the heat transfer by convection between the three internal surfaces of the cavity, there is no direct methodology due to the geometry, which involves the relationship between unconventional surfaces; however, using a series of dimensionless groups it is possible to apply it to a great variety of cases with pertinent modifications.

The cavity is approximated as two concentric cylinders, as done by Veynandt [32], modyfing the Raithby and Hollands correlation [37], to define the convection for the surfaces (3: outer tube, 4: CPC surface, and 6: inner window) as:

$$
\dot{q}_{i, \text { conv }}^{\prime}=f(\operatorname{Ra}, \operatorname{Pr})\left(T_{i}-T_{c}\right)
$$

where $f(\mathrm{Ra}, \mathrm{Pr})$ is the corrected Raithby and Hollands correlation to the average cavity temperature $T_{c}$ as defined by Veynandt [32]. The convection $\dot{q}_{58, \text { conv }}$ can be determined by the Churchill and Chu correlation [38] for free-convection, and for forced convection, the Churchill and Bernstein [39] or Žukauskas [40] correlation can be used. The convection $\dot{q}_{78, \text { conv }}^{\prime}$ can be estimated with McAdams correlation for free-convection, and Pohlhausen [41] or Chilton and Colburn [42] correlations for forced convection.

Internal convection $\left(\dot{q}_{21, \text { conv }}^{\prime}\right)$ is divided into two zones (involving the three fluid regimes): For single-phase fluids, the Gnielinski correlation is applied [42], and the Gungor and Winterton [43] correlation for the two-phase fluid. 


\subsection{Radiation Heat Fluxex}

The radiation heat fluxes in the cavity are determined with the radiosity and the view factors for each surface (3: outer tube, 4: CPC surface, and 6: inner window) as:

$$
\dot{q}_{i, r a d}^{\prime}=\varepsilon_{i} \sigma T_{i}^{4}+\left(1-\varepsilon_{i}\right) \sum_{j} J_{j} F_{i-j}
$$

where $\varepsilon_{i}$ is the emissivity, $T_{i}$ is the surface temperature, $J_{j}$ is the radiosity and $F_{i-j}$ is the view factor determined by the geometry of each surface $\left(F_{3-6}=0.2962, F_{3-4}=0.7038\right.$, $\left.F_{4-3}=0.9036, F_{4-6}=0.0964, F_{6-4}=0.1814, F_{6-3}=0.8186\right)$. For the $\dot{q}_{58, \text { rad }}^{\prime}$ and $\dot{q}_{78, \text { rad }}^{\prime}$, the Stefan-Boltzmann equation is applied.

\subsection{Conduction Heat Fluxes}

Except for $\dot{q}_{s p t, c o n d}^{\prime}$, which is modelled as a semi-infinite fin [44], all the terms are calculated with the appropriate Fourier equation for conduction (plane and circular wall).

\subsection{Thermal Model Validation}

Although there are seven balance equations, the model consists of 29 Equations and 29 unknowns grouped into the final seven equations of Equations (1)-(7). The seven groups are defined below:

- Group 1: four solar absorption equations $\left(\dot{q}_{3, \text { Sol Abs }}^{\prime}, \dot{q}_{4, \text { SolAbs }}^{\prime}, \dot{q}_{5, \text { Sol Abs }}^{\prime}, \dot{q}_{7, \text { SolAbs }}^{\prime}\right)$.

- Group 2: four conduction equations $\left(\dot{q}_{32, \text { cond }}^{\prime}, \dot{q}_{s p t, c o n d}^{\prime}, \dot{q}_{45, \text { cond }}^{\prime}, \dot{q}_{67, \text { cond }}^{\prime}\right)$.

- Group 3: six convection equations $\left(\dot{q}_{21, \mathrm{conv}}^{\prime}, \dot{q}_{3, \mathrm{conv}}^{\prime}, \dot{q}_{4, \mathrm{conv}}^{\prime}, \dot{q}_{58, \mathrm{conv}}^{\prime}, \dot{q}_{6, \mathrm{conv}}^{\prime}, \dot{q}_{78, \mathrm{conv}}^{\prime}\right)$.

- $\quad$ Group 4: five radiation equations $\left(\dot{q}_{3, \mathrm{rad}}^{\prime}, \dot{q}_{4, \mathrm{rad}}^{\prime}, \dot{q}_{58, \mathrm{rad}}^{\prime}, \dot{q}_{6, \mathrm{rad}}^{\prime}, \dot{q}_{78, \mathrm{rad}}^{\prime}\right)$.

- Group 5: three radiosity equations.

- Group 6: seven balances (one per node).

- Group 7: fluid balance to calculate the enthalpy increase of the fluid.

To solve the non-linear model, the methodology proposed by Adiutori [21] was used to directly solve the temperatures and heat fluxes instead of an iterative method. With this methodology, the convective coefficients are transformed by the functional relations of the heat flow and temperatures, so solving by iterative methods was avoided, resulting in a fast computation with an appropriate convergence with high accuracy $[21,45,46]$. However, this does not exclude the numerical solution to each heat collection element (HCE) of $5.88 \mathrm{~m}$ [33].

To validate the model, the analysis parameters from Montes et al. [15] were tested, and the system of equations was solved to obtain the temperatures and heat fluxes involved in the receiver. The results were compared with the thermal losses of the FRESDEMO field determined by Montes et al. [15] and Mertins [47], as shown in Figure 6. The thermal losses of the proposed model were in between those obtained by Montes et al. [15] and Mertins [47], which demonstrated its validation. At the beginning of the loop, the proposed model showed a greater heat loss than those of Montes et al. [15] and Mertins [47]. This variation is because the present model considered the heat losses associated with the first support placed at the beginning of the loop. However, the error in this zone was less than $5 \%$. 


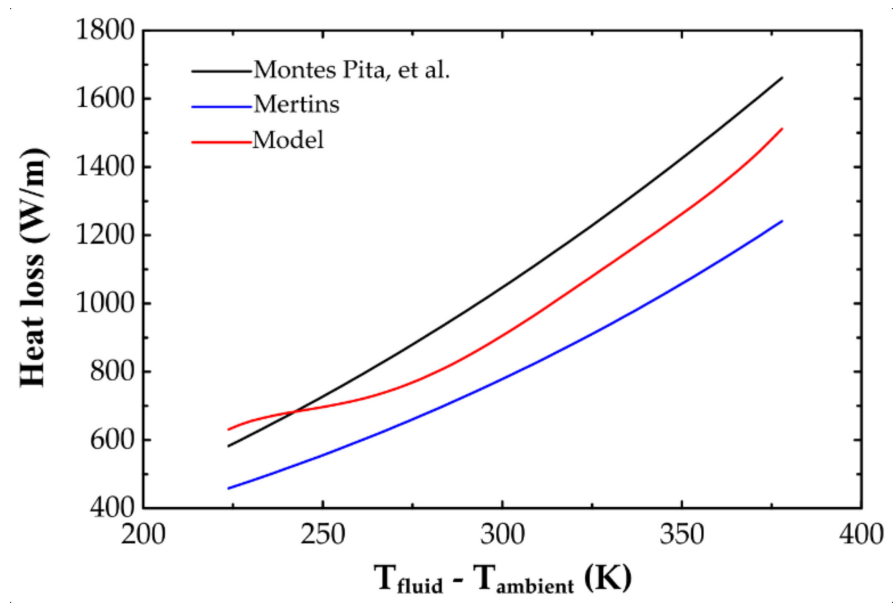

Figure 6. Comparison between the thermal losses calculated by the thermal model of Montes et al. [15]; thermal model of Mertins [47], and proposed model.

\section{Thermo-Hydraulic Performance and Characterization of the System}

Once the thermo-hydraulic model was validated, it was directly applied to a case study to establish the lengths of the loops comprising the solar field and to evaluate the energy and exergy efficiencies of the loops. Three characteristic simulation days were chosen: the design day (21 June), the day with the greatest insolation (21 May), and the day with the lowest insolation (21 September). Thus, the results could be generalized to any day of the year; the efficiency lay between the limits of the highest and lowest insolation. The software Meteonorm [48] was used to establish the initial climatological conditions for the model, which are summarized in Table 6.

Table 6. Weather conditions for Agua Prieta, Sonora.

\begin{tabular}{cccc}
\hline Parameter & 21 June & 21 May & 21 September \\
\hline Condition & Design day & Greatest insolation & Lowest insolation \\
Day of the year & 172 & 141 & 264 \\
Atmospheric & 0.886 & 0.884 & 0.885 \\
pressure(bar) & & & \\
Ambient & 300.05 & 295.95 & 296.95 \\
temperature $(\mathrm{K})$ & 271.95 & 265.75 & 277.75 \\
Effective sky & 856.4815 & 889.6396 & 628.8580 \\
temperature $(\mathrm{K})$ & 4 & 4.1 & 3.2 \\
DNI $\left(\mathrm{W} / \mathrm{m}^{2}\right)$ & & &
\end{tabular}

The simulations were divided into two groups corresponding to the two configurations of the power block described in Section 2. Both cycles were designed to obtain the same net power output (10 MW); however, the number of extractions, mass flow rate, and inlet temperature of the working fluid were modified. Varying these parameters affected the solution of the heat transfer model. Note that the usual operation mode of solar plants is recirculation, where an intermediate water/steam separator is between the preheating and superheating boiling zones [49]. In the present study, the once-through mode was adopted because the scope was limited to determine the thermal behavior of the system.

To solve the model, the mass flow needed to be divided into $N$ loops. The mass flow could not exceed $4.5 \mathrm{~kg} / \mathrm{s}$ for each loop so that the HTF velocity is approximately the same as in PTC [15]. Thus, different configurations for the solar field can be determined depending on the number of loops that are used, which will affect the total length of the field [4]. The two-steam extraction cycle requires a total mass flow of $12.81 \mathrm{~kg} / \mathrm{s}$. Under this restriction, three loops of $4.27 \mathrm{~kg} / \mathrm{s}$ and four loops of $3.20 \mathrm{~kg} / \mathrm{s}$ are considered. The 
three-steam extraction cycle requires a total mass flow of $13.26 \mathrm{~kg} / \mathrm{s}$, so three loops of $4.42 \mathrm{~kg} / \mathrm{s}$ and four loops of $3.32 \mathrm{~kg} / \mathrm{s}$ are considered.

Therefore, each case was analyzed by considering three and four loops to ensure an adequate mass flow according to the specified limits. Figure 7 shows a diagram of the analysis cases, which resulted in a total of 12 simulations.

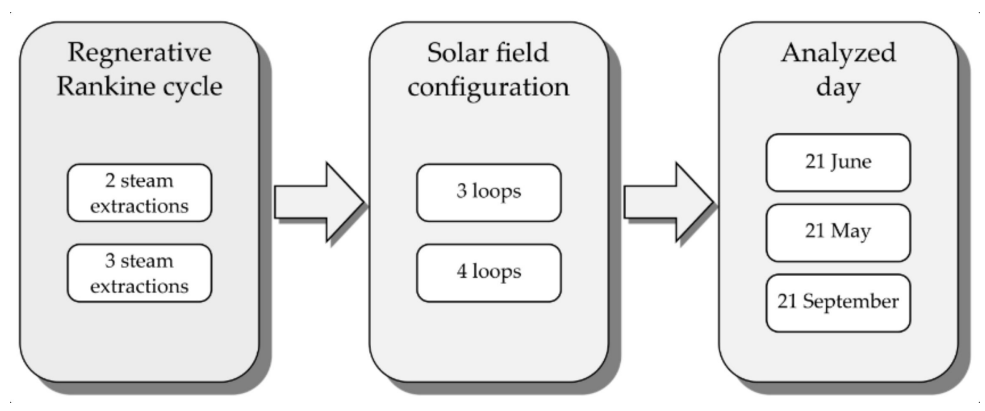

Figure 7. Simulation cases.

\subsection{Three Loops Solar Fields}

Figure 8 graphs the required lengths of the loops to heat steam up to $673.15 \mathrm{~K}$ on the three analyzed days for two steam extractions (Figure 8a) and for three steam extractions (Figure 8 b). Table 7 summarizes the size of each section of the solar field.

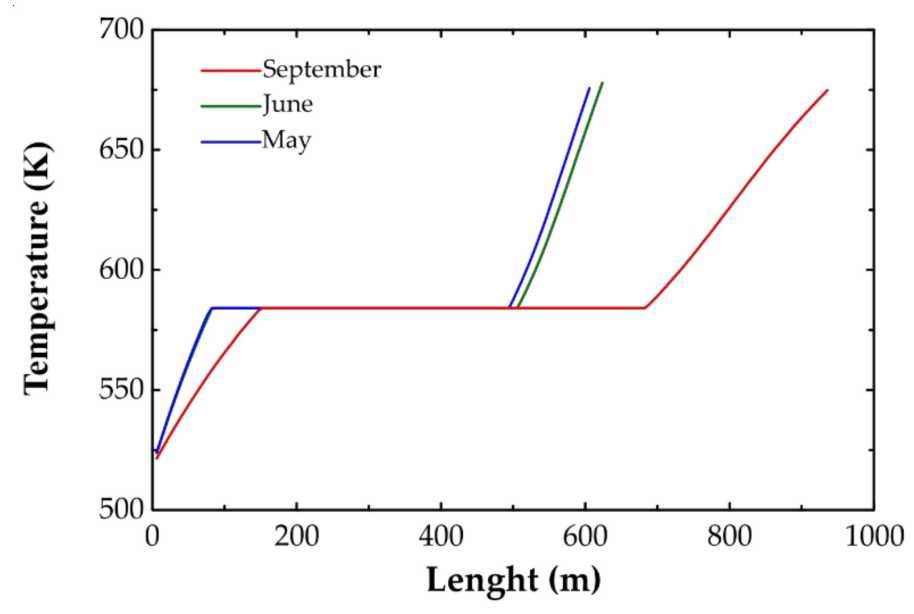

(a)

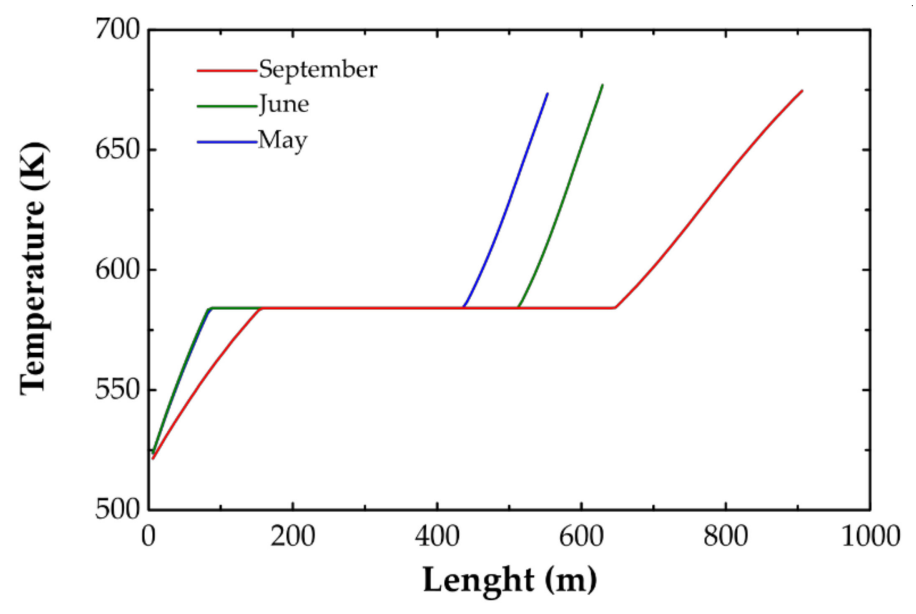

(b)

Figure 8. Water/steam temperature along an LFR with three loops in once-through operation mode: (a) Two steam extractions; (b) Three steam extractions.

Table 7. Three loop LFR solar field.

\begin{tabular}{ccccccc}
\hline \multirow{2}{*}{ Section } & \multicolumn{3}{c}{ Two Steam Extractions } & \multicolumn{3}{c}{ Three Steam Extractions } \\
\cline { 2 - 7 } & June & May & September & June & May & September \\
\hline Pre-heating (m) & 88.6 & 86.6 & 161.4 & 91.5 & 89.4 & 156.1 \\
Evaporation (m) & 423.9 & 408.1 & 479.8 & 456.6 & 425.7 & 533.4 \\
Superheating (m) & 111 & 105.6 & 264.7 & 119.5 & 111 & 245.9 \\
Length per loop (m) & 623.5 & 600.2 & 905.9 & 667.6 & 626.1 & 935.5 \\
Total length $^{1}(\mathrm{~km})$ & 1.87 & 1.8 & 2.7 & 2 & 1.9 & 2.8 \\
\hline
\end{tabular}

${ }^{1}$ : Since the solar field consists of three loops, the total length is multiplied by 3 . 


\subsection{Four Loops Solar Fields}

Figure 9 graphs the required lengths of the loops to heat steam up to $673.15 \mathrm{~K}$ on the three analyzed days for two steam extractions (Figure 9a) and for three steam extractions (Figure 9 b). Table 8 summarizes the size of each section of the solar field.

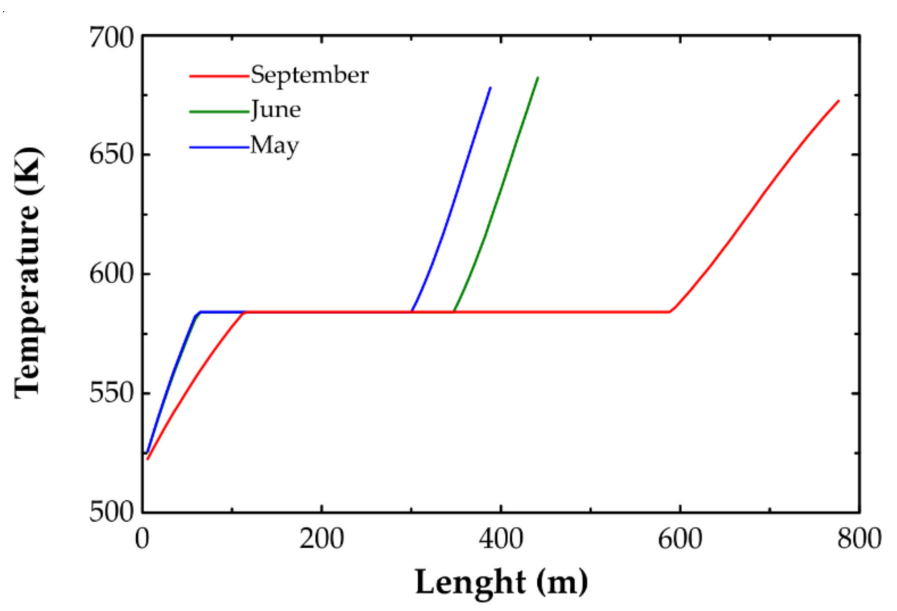

(a)

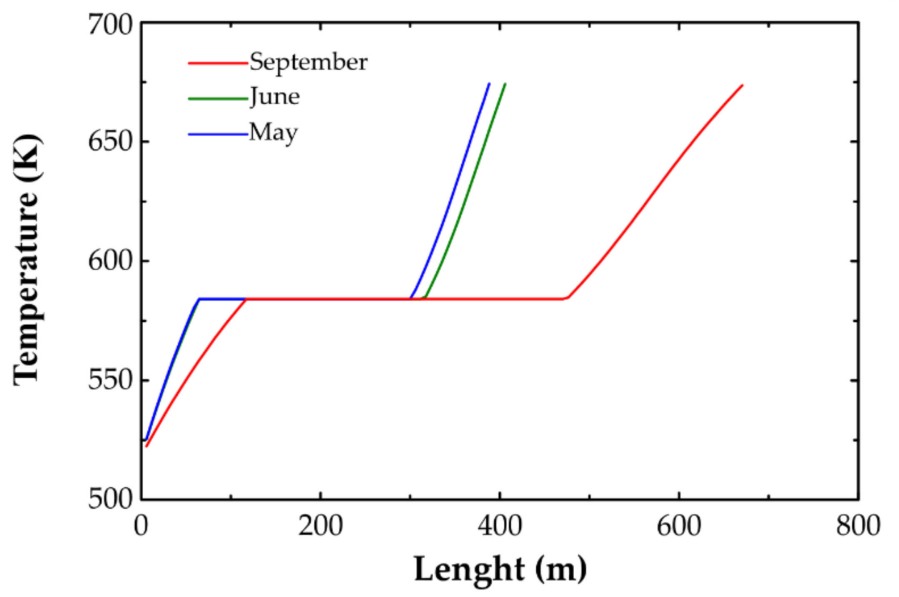

(b)

Figure 9. Water/steam temperature along an LFR with four loops in once-through operation mode: (a) Two steam extractions; (b) Three steam extractions.

Table 8. Three loop LFR solar field.

\begin{tabular}{ccccccc}
\hline \multirow{2}{*}{ Section } & \multicolumn{3}{c}{ Two Steam Extractions } & \multicolumn{3}{c}{ Three Steam Extractions } \\
\cline { 2 - 7 } & June & May & September & June & May & September \\
\hline Pre-heating $(\mathrm{m})$ & 68.4 & 66.8 & 119.3 & 70.5 & 68.9 & 123.3 \\
Evaporation $(\mathrm{m})$ & 274.8 & 239.6 & 476 & 247 & 233.8 & 353.1 \\
Superheating $(\mathrm{m})$ & 93.8 & 81.8 & 181.1 & 83.9 & 81.2 & 190.3 \\
Length per loop $(\mathrm{m})$ & 437 & 1.6 & 776.5 & 401.4 & 383.9 & 667.7 \\
Total length $^{1}(\mathrm{~km})$ & 1.7 & 1.6 & 3.1 & 1.6 & 1.5 & 2.7 \\
\hline
\end{tabular}

${ }^{1}$ : Since the solar field consists of four loops, the total length is multiplied by 4 .

\subsection{Dimensions of the Solar Field Loops}

The previous Figures show that the longest solar field was on 21 September because this day had the lowest insolation. This was defined as the minimum required length so that the solar plant can deliver the thermal power output required by the power block through the year and continuously operate under nominal conditions (i.e., design point). An important parameter associated with the size of the solar field and power output under nominal operating conditions is the ratio between the average real use and available capacity $[49,50]$. This ratio gives an idea of how oversized the solar field is relative to the power block and is known as the solar multiple. This is defined as the thermal power supplied by the solar field divided by the thermal power required by the power block to work under nominal conditions:

$$
S M=\frac{\dot{Q}_{t h, \text { solar field }}}{\dot{Q}_{\text {th, power block }}}
$$

A solar multiple greater than unity can be chosen so that the turbine operates under stationary conditions for a longer time interval rather than if the field were sized to the required thermal power at a single point. Figure 10 shows the relationship between thermal 
power and time for the design and indicates the possible incorporation of an energy storage system.

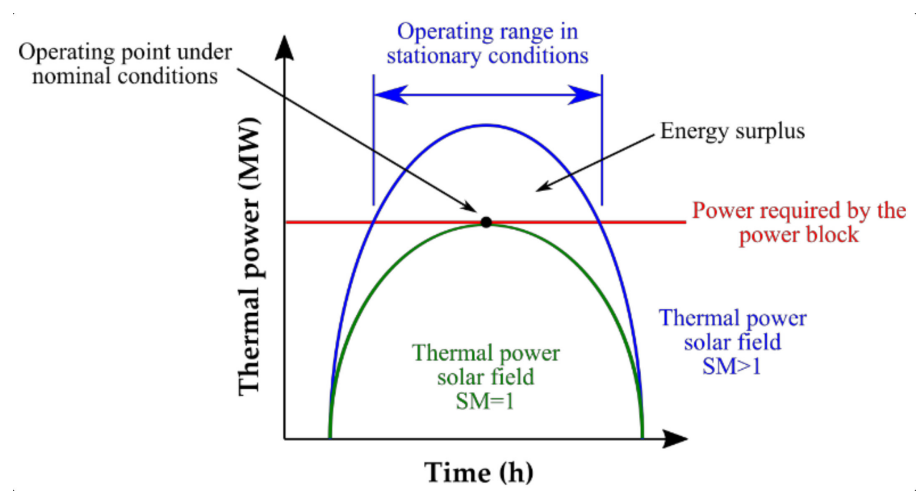

Figure 10. Effects of sizing the solar field with different solar multiples.

\subsection{Solar Field for a Two-Steam Extraction Regenerative Rankine Cycle Power Block}

A solar field with three loops required a length of $935.5 \mathrm{~m}$ per loop (total length of $2.8 \mathrm{~km})$, which implies a total concentration area $\left(A_{p m}\right)$ of $0.059 \mathrm{~km}^{2}$. Similarly, for a solar field with four loops required $776.5 \mathrm{~m}$ per loop (total length of $3.1 \mathrm{~km}$ ), which implies a total concentration area of $0.065 \mathrm{~km}^{2}$. Figure 11 shows schematic images of the condition.

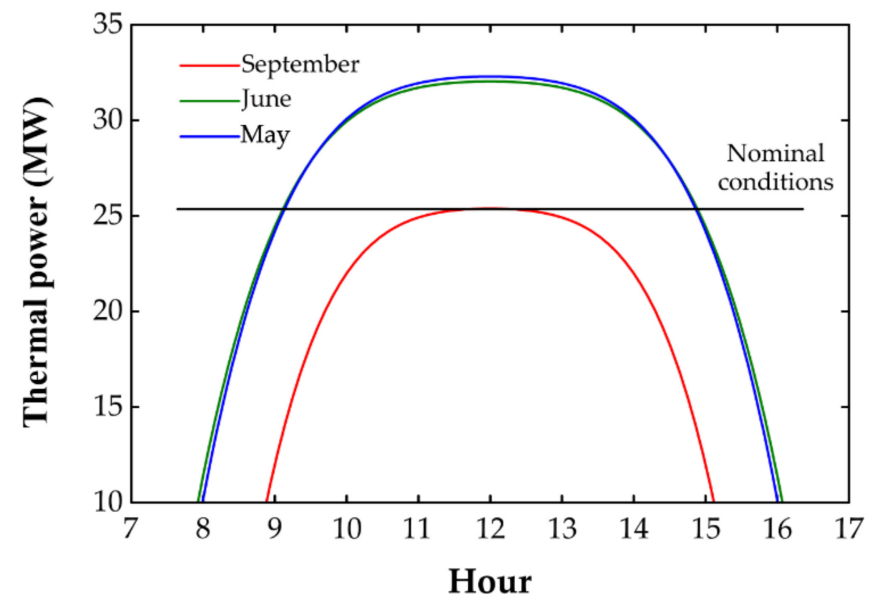

(a)

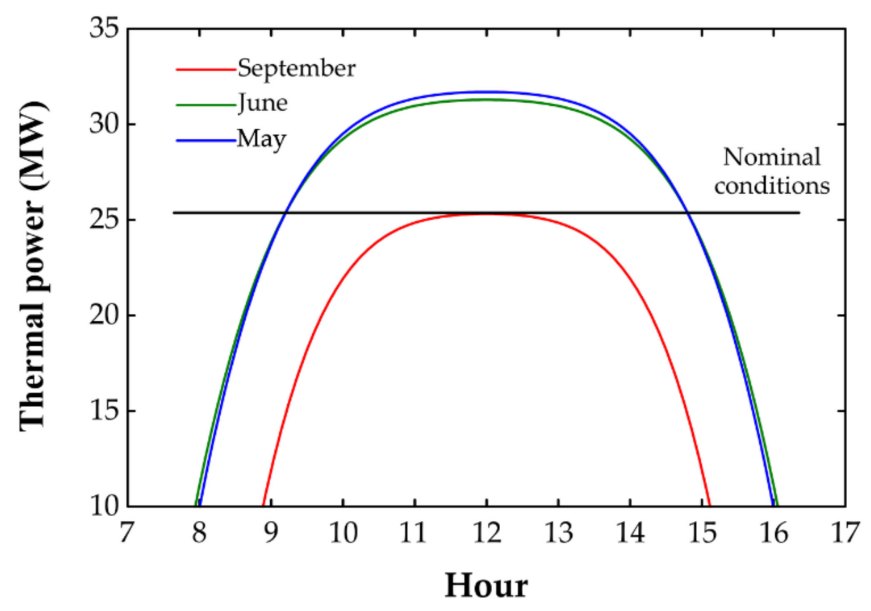

(b)

Figure 11. Solar multiple for two steam extractions: (a) Three loops; (b) Four loops.

\subsection{Solar Field for a Three-Steam Extraction Regenerative Rankine Cycle Power Block}

A solar field with three loops required a length of $905.9 \mathrm{~m}$ per loop (total length of $2.7 \mathrm{~km}$ ), which implies a total concentration area of $0.057 \mathrm{~km}^{2}$. Similarly, a solar field with four loops required $776.5 \mathrm{~m}$ per loop (total length of $3.1 \mathrm{~km}$ ), which implies a total concentration area of $0.065 \mathrm{~km}^{2}$. Figure 12 shows schematic images of the condition. 


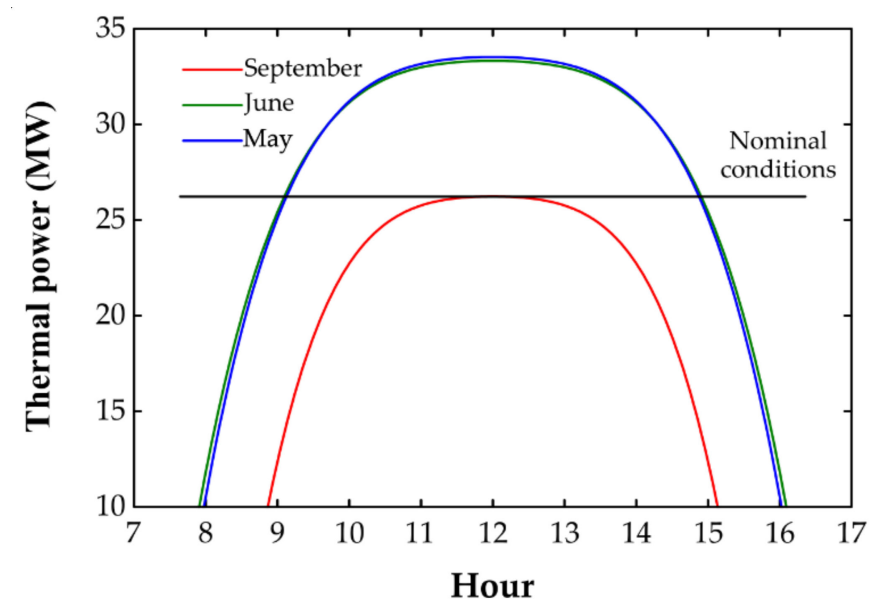

(a)

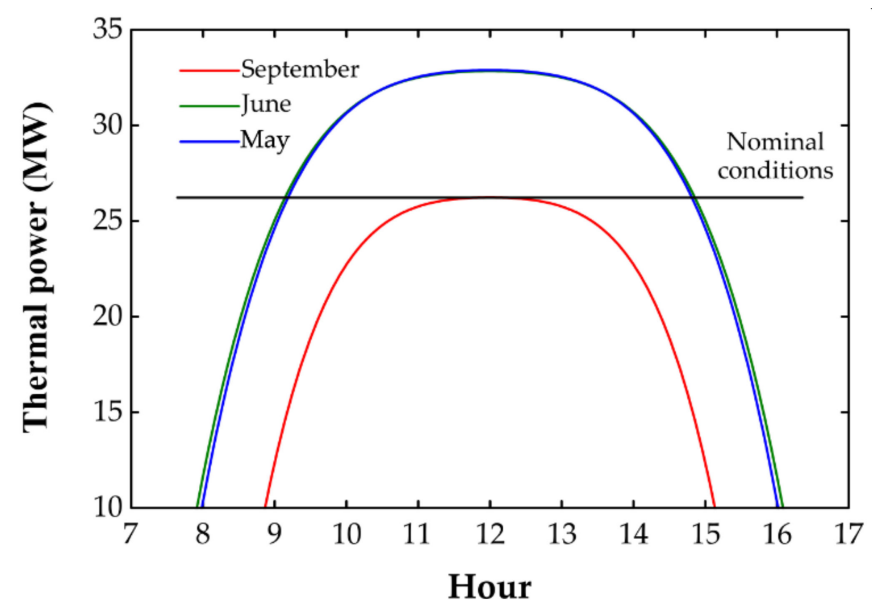

(b)

Figure 12. Solar multiple for two steam extractions: (a) Three loops; (b) Four loops.

\subsection{Solar Field Layout and Length}

A shorter pipe system requires fewer of the elements discussed above. In general, a solar field has two possible configurations: the ' $\mathrm{H}$ ' configuration (where the solar field is divided into four sections (north east, north west, south east, and south west) with the power block positioned in the center) for fields with a concentration area of greater than $400,000 \mathrm{~m}^{2}\left(0.4 \mathrm{~km}^{2}\right)$, and the ' $\mathrm{I}$ ' configuration (where the solar field is divided into two sections (east and west) with the power block located in the center) for fields with a concentration area of less than $400,000 \mathrm{~m}^{2}\left(0.4 \mathrm{~km}^{2}\right)[4,49]$. The length of each loop for the FRESDEMO field was limited to $1000 \mathrm{~m}$. Together with that of mass flow, this restriction delimited the number of loops required by the solar field.

Simulations with three and four loops for September obtained maximum lengths of $935.5 \mathrm{~m}$ and $776.5 \mathrm{~m}$, respectively, for two extractions. Similarly, maximum lengths of 905.9 $\mathrm{m}$ and $666.7 \mathrm{~m}$, respectively, were obtained for three extractions. These were chosen as the design configurations, and the solar multiple was determined for the days with the greatest insolation, as summarized in Table 9.

Table 9. Solar multiple.

\begin{tabular}{ccccccc}
\hline \multirow{2}{*}{ Case } & \multicolumn{3}{c}{ Two Steam Extractions } & \multicolumn{3}{c}{ Three Steam Extractions } \\
\cline { 2 - 7 } & June & May & September & June & May & September \\
\hline Three & 1.262 & 1.272 & 1 & 1.235 & 1.251 & 1 \\
loops & 1.269 & 1.277 & 1 & 1.251 & 1.253 & 1 \\
Four loops & 1.253 &
\end{tabular}

In all cases, the solar multiple was not as excessive for systems without energy storage as reported in the literature, which makes these configurations acceptable, even though the dispatchability of energy is limited by the transient conditions, further studies must be carried out to determine the size and configuration of TES. As the field was relatively small, the loops were arranged in the 'I' configuration. Figure 13 compares the decreases in the loop length with the optical optimization. 


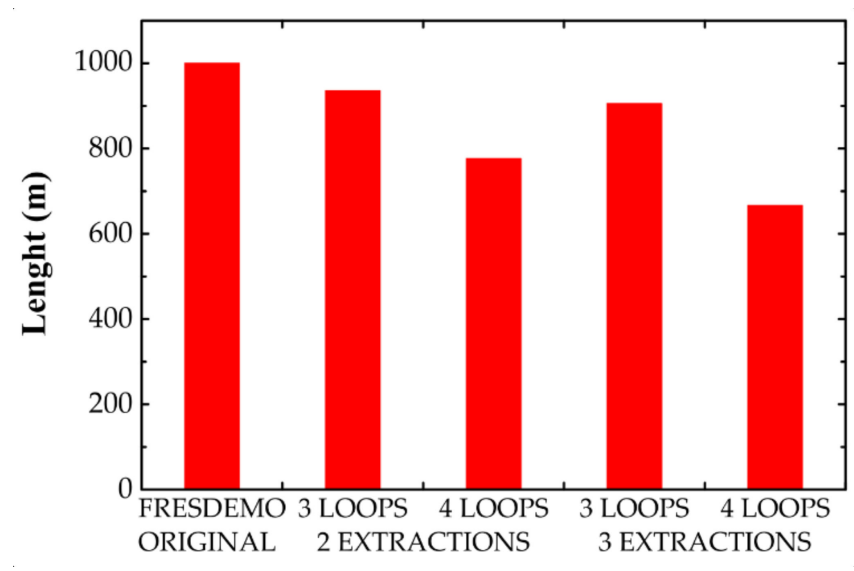

Figure 13. Comparison of the length of the simulated loops.

\subsection{Energy and Exergy Efficiency}

Once the loop length was determined, the energy and exergy efficiency were calculated for the receiver and whole LFR with Equations (14)-(17).

$$
\begin{gathered}
\eta_{I, r e c}=\frac{\dot{Q}_{H T F}}{\dot{Q}_{r e c}} \\
\eta_{I, L F R}=\frac{\dot{Q}_{H T F}}{\dot{Q}_{P M}} \\
\eta_{I I, r e c}=\frac{\dot{B}_{H T F}}{\dot{B}_{r e c}} \\
\eta_{I I, L F R}=\frac{\dot{B}_{H T F}}{\dot{B}_{P M}}
\end{gathered}
$$

where $\dot{Q}_{H T F}$ is the heat gain rate of the HTF, $\dot{Q}_{r e c}$ is the heat rate impinging the receiver, $\dot{Q}_{P M}$ is the heat rate captured by the primary mirrors, $\dot{B}_{H T F}$ is the exergy heat gain rate of the HTF, $\dot{B}_{r e c}$ is the heat exergy rate impinging the receiver, and $\dot{B}_{P M}$ is the radiative exergy rate captured by the primary mirrors according to Parrot's formulation [51].

The thermal efficiency analysis of the receiver and concentrator showed a significant decrease in efficiency after the phase change. In the first HCE, the efficiencies of the concentrator and receiver were 0.37 and 0.63 , respectively; at the exit of the loop, these fall to 0.14 and 0.24 , respectively. This decrease in energy efficiency is shown in Figure 14.

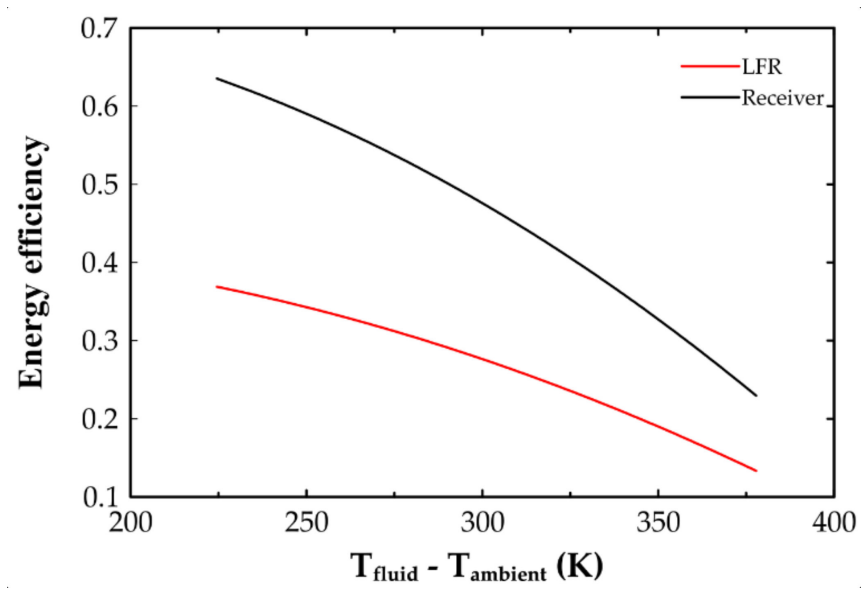

Figure 14. Thermal efficiency of the LFR and the receiver. 
The exergy efficiency of the receiver behaved differently compared to the energy efficiency, but the exergy efficiency of the concentrator did not, as shown in Figure 15. This is because the energy efficiency decreases with an increased working temperature because of the increased heat loss, while the exergy efficiency increases with temperature but not as much at higher temperatures. In the first HCE, the exergy efficiencies of the concentrator and receiver were 0.60 and 0.14 , respectively; at the exit of the loop, these became 0.23 and 0.19 , respectively.

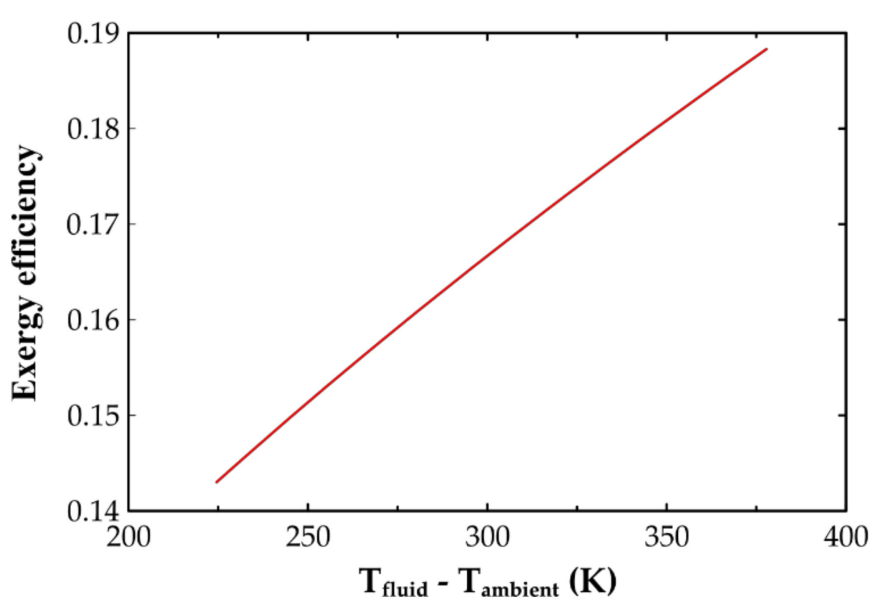

(a)

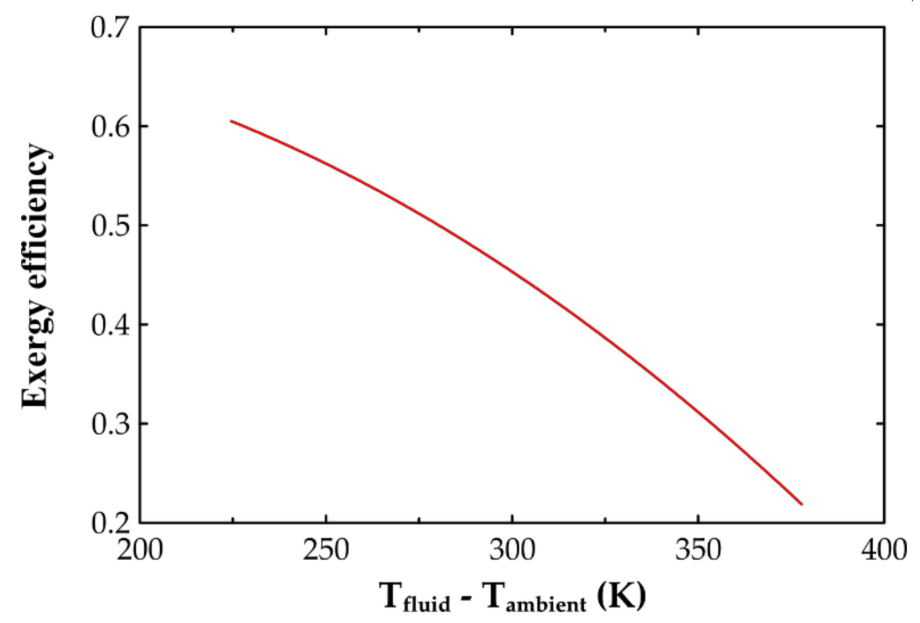

(b)

Figure 15. Exergy efficiency: (a) Receiver; (b) LFR.

Figure 16a graphs the increase in heat loss per unit length against the difference in temperature between the fluid and environment. The heat losses increased too much once the superheated steam regime was reached. The pressure drop showed similar behavior (Figure 16b). In the superheated steam regime, the pressure loss became more evident and reached close to 0.1 bar.

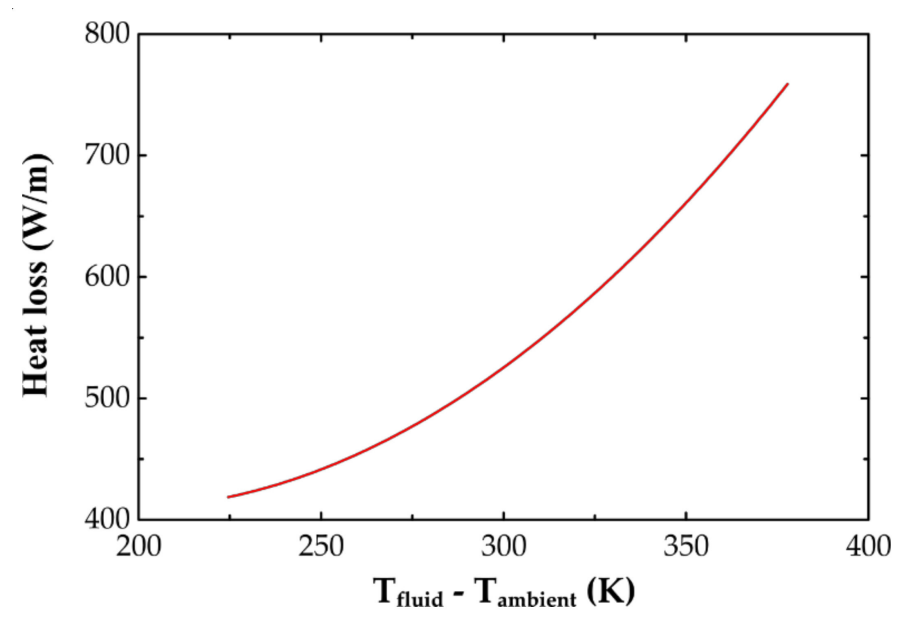

(a)

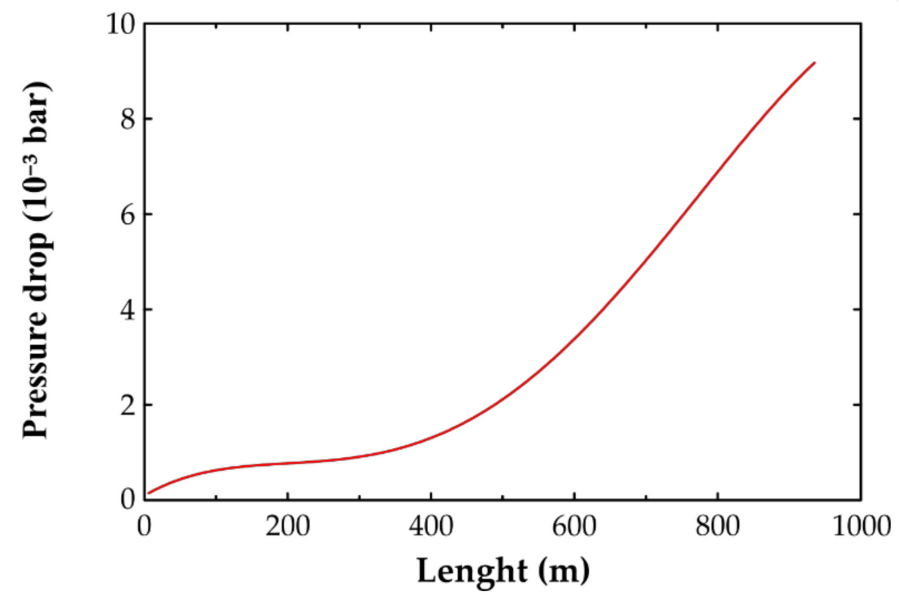

(b)

Figure 16. General losses in the solar field: (a) Heat loss; (b) Pressure drop.

With the computation of heat loss (Figure 16a) and pressure drop (Figure 16b) across the solar field, an important observation can be formulated comparing these two parameters. Bejan [22,52] has proposed the irreversibility distribution ratio, Equation (18), while Paoletti [53] defined the Bejan number, Equation (18), as dimensionless groups to compare the irreversibility between heat transfer and pressure drop. Alternatively, instead of the 
entropy generation terms in Equations (18) and (19), exergy destruction terms can be considered as shown, where the meaning of $\phi$ and Be remains the same.

$$
\begin{aligned}
& \phi=\frac{\dot{S} \prime_{\text {gen }, \Delta p}}{\dot{S}_{g_{\text {gen },}, \dot{Q}_{l}^{\prime}}}=\frac{\dot{B}_{\text {dest }, \Delta p}}{\dot{B}_{\text {dest }, \dot{Q}_{l}^{\prime}}} \\
& \mathrm{Be}=(1+\phi)^{-1}
\end{aligned}
$$

Accordingly, it can be concluded that when $\mathrm{Be} \rightarrow 1$, the heat transfer irreversibility dominates, while when Be $\rightarrow 0$ the irreversibility is dominated by the pressure drop. The exergy destruction by heat loss and pressure drop can be quantified by:

$$
\begin{gathered}
\dot{B}_{\text {dest }, \Delta p}=T_{a m b} \frac{1}{T_{1}} \frac{\dot{m}}{\rho} \Delta p \\
\dot{B}_{\text {dest } \dot{Q}_{l}}=T_{a m b} \frac{1}{T_{1}} \dot{Q}_{l}^{\prime}
\end{gathered}
$$

where $T_{a m b}=300 \mathrm{~K}$ is the ambient temperature, $T_{1}$ is the HTF temperature, $\dot{m}$ is the mass flow rate, $\Delta p$ is the pressure drop, and $\dot{Q}_{l}^{\prime}$ is the heat loss rate. For the optimized field, $\mathrm{Be}=0.9975$, so the heat losses dominate the irreversibilities across the solar field.

\subsection{Comparison of the Optimized Field and FRESDEMO}

With the previous data, a comparison regarding the $2 \mathrm{E}$ analysis performed on the optimized field and the reported values for FRESDEMO by Montes et al. [15] is described in Table 10.

Table 10. Comparison of 2E analysis between FRESDEMO [15] and the optimized field.

\begin{tabular}{ccc}
\hline Parameter & FRESDEMO & Optimized Field \\
\hline Energy efficiency & $67 \%$ & $64 \%$ \\
Exergy efficiency & $63 \%$ & $60 \%$ \\
Bejan number & $0.9901^{1}$ & 0.9975 \\
Maximum length (m) & 1000 & 935 \\
Maximum SM & - & 1.27 \\
\hline
\end{tabular}

1: This parameter was not determined by Montes et al. [15], but determined with the reported data.

\section{Conclusions}

A novel study of the design of a solar power plant is discussed. The solar plant can supply the required thermal power through a regenerative Rankine cycle with two and three steam extractions. The power cycles were determined under the assumption that the exergetic efficiency of the entire system should be optimized, which implies that the largest amount of useful energy can be used. Thus, a sensibility analysis was performed to optimize the extraction pressures of the turbine to minimize the total destroyed exergy.

Once the required thermal power output of the solar field was determined, the number of loops was established for power cycles with two and three steam extractions considering the maximum $(4.5 \mathrm{~kg} / \mathrm{s})$ and minimum mass flows $(2 \mathrm{~kg} / \mathrm{s})$ of LFRs plants. Two alternatives were considered for each case: three and four loops. The analysis was performed for the average day (21 June), day of greatest insolation (21 May), and day of lowest insolation (21 September), to determine both the surface temperature and length of each loop applying Adiutori's methodology [21] to solve the thermal model.

The length of each loop was limited to the length of the FRESDEMO field (1000 m). This restriction together with the mass flow restriction delimited the number of loops required by the solar field. The simulation results showed that the maximum loop length for three and four loops on 21 September was $905.9 \mathrm{~m}$ and $776.5 \mathrm{~m}$, respectively, for two 
extractions, and $935.5 \mathrm{~m}$ and $667.6 \mathrm{~m}$, respectively, for three extractions. As stated above, it was expected that using an optically optimized field would reduce the length of the loops. Under the cases analyzed, the decrease in length varies from $6.45 \%$ to $33.3 \%$; while keeping a solar multiple between 1.25 and 1.27.

These were chosen as the design configurations, and the solar multiple was determined for the day with the highest insolation. In all cases, the solar multiple did not exceed that for systems without energy storage as reported in the literature. Thus, these configurations are ideal for future implementation.

Contrary to what is thought, when a concentration system is optically optimized, thermal efficiency is negatively affected $[50,54]$. Comparing the results of the optimized Field with FRESDEMO [15], the optimized field presents an increase in optical efficiency of $28 \%$, resulting in thermal efficiency decreases of less than $5 \%$; with the advantage that the length of the loop has decreased; while the irreversibility across the solar field presents a similar behavior between the pressure drop and the heat loss.

When comparing the decrease in thermal efficiency against the decrease in the length of the loop, it may be beneficial to sacrifice a little thermal efficiency since the system costs would go down. Future studies could fruitfully explore this issue further by comparing the behavior of the optimized Fresnel reflector and a parabolic through solar field in order to establish a criterion for future implementation.

Author Contributions: Conceptualization, E.G.-M. and M.D.D.-G.; methodology, E.G.-M.; software, E.G.-M.; validation, E.G.-M. and M.D.D.-G.; formal analysis, E.G.-M.; investigation, E.G.-M. and M.D.D.-G.; resources, M.D.D.-G.; data curation, E.G.-M.; writing—original draft preparation, E.G.-M.; writing-review and editing, M.D.D.-G. and E.G.-M.; visualization, E.G.-M.; supervision, M.D.D.-G.; project administration, M.D.D.-G.; funding acquisition, M.D.D.-G. All authors have read and agreed to the published version of the manuscript.

Funding: E.G.-M. acknowledges funding by CONACYT through a graduate scholarship 863595/628521.

Institutional Review Board Statement: Not applicable.

Informed Consent Statement: Not applicable.

Conflicts of Interest: The authors declare no conflict of interest.

\section{References}

1. BP. Statistical Review of World Energy. 2018. Available online: https://www.bp.com/en/global/corporate/energy-economics/ statistical-review-of-world-energy.html (accessed on 15 February 2019).

2. Bernhard, R.; Laabs, H.-J.; de LaLaing, J.; Eickhoff, M. Linear Fresnel Collector Demonstration on the PSA, Part I-Design, Construction and Quality Control. In Proceedings of the International Symposium on Concentrated Solar Power and Chemical Energy Technologies, Casablanca, Morroco, 2-5 October 2008; Available online: https:/ /www.researchgate.net/publication/2250 00351_Linear_Fresnel_Collector_Demonstration_on_the_PSA_Part_I_-_Design_Construction_and_Quality_Control (accessed on 10 July 2021).

3. González-Mora, E.; Durán García, M.D. Methodology for an Opto-Geometric Optimization of a Linear Fresnel Reflector for Direct Steam Generation. Energies 2020, 13, 355. [CrossRef]

4. Montes Pita, M.J. Análisis Y Propuestas De Sistemas Solares De Alta Exergía Que Emplean Agua Como Fluido Calorífero. Ph.D. Thesis, Universidad Politécnica de Madrid, Madrid, Spain, 2008.

5. Almanza, R.; Lentz, A. Electricity production at low powers by direct steam generation with parabolic troughs. Sol. Energy 1998, 64, 115-120. [CrossRef]

6. Almanza, R.; Lentz, A.; Jiménez, G. Receiver behavior in direct steam generation with parabolic troughs. Sol. Energy 1997, 61, 275-278. [CrossRef]

7. Cui, W.; Li, H.; Li, L.; Liao, Q. Thermal stress analysis of DSG solar absorber tube in stratified two-phase regime. AIP Conf. Proc. 2013, 1558, 2217-2220.

8. Eck, M.; Zarza, E.; Eickhoff, M.; Rheinländer, J.; Valenzuela, L. Applied research concerning the direct steam generation in parabolic troughs. Sol. Energy 2003, 74, 341-351. [CrossRef]

9. Zarza Moya, E. Generación Directa de Vapor con Colectores Solares Cilindro Parabólicos. Proyecto DIrect Solar Steam (DISS). Ph.D. Thesis, Universidad de Sevilla, Sevilla, Spain, 2003.

10. IEA. Technology Roadmap-Solar Thermal Electricity; IEA: Paris, France, 2014.

11. NREL. Concentrating Solar Power Projects. Available online: https:/ / solarpaces.nrel.gov / (accessed on 20 March 2020). 
12. IRENA. Solar Energy. Available online: https://www.irena.org/solar (accessed on 27 February 2021).

13. Elsafi, A.M. Exergy and exergoeconomic analysis of sustainable direct steam generation solar power plants. Energy Convers. Manag. 2015, 103, 338-347. [CrossRef]

14. Schenk, H.; Hirsch, T.; Fabian Feldhoff, J.; Wittmann, M. Energetic comparison of linear Fresnel and parabolic trough collector systems. J. Sol. Energy Eng. 2014, 136, 041015. [CrossRef]

15. Montes, M.J.; Barbero, R.; Abbas, R.; Rovira, A. Performance model and thermal comparison of different alternatives for the Fresnel single-tube receiver. Appl. Therm. Eng. 2016, 104, 162-175. [CrossRef]

16. Hakkarainen, E.; Tähtinen, M.; Mikkonen, H. Dynamic model development of linear Fresnel solar field. In Proceedings of the ASME 2015 Power and Energy Conference, New York, NY, USA, 2-28 July 2015.

17. Giostri, A.; Binotti, M.; Silva, P.; Macchi, E.; Manzolini, G. Comparison of two linear collectors in solar thermal plants: Parabolic trough versus Fresnel. J. Sol. Energy Eng. 2013, 135, 011001. [CrossRef]

18. Hirsch, T.; Khenissi, A. A systematic comparison on power block efficiencies for CSP plants with direct steam generation. Energy Procedia 2013, 49, 1165-1176. [CrossRef]

19. Sun, J.; Liu, Q.; Hong, H. Numerical study of parabolic-trough direct steam generation loop in recirculation mode: Characteristics, performance and general operation strategy. Energy Convers. Manag. 2015, 96, 287-302. [CrossRef]

20. Hakkarainen, E.; Kannari, L. Dynamic Modelling of Concentrated Solar Field for Thermal Energy Storage Integration. In Proceedings of the 9th International Renewable Energy Storage Conference (IRES 2015), Düsseldorf, Germany, 9-11 March 2015.

21. Adiutori, E. The New Engineering, 3rd ed.; Ventuno Press: Naples, FL, USA, 2017; ISBN 978-0-9626220-4-5.

22. Bejan, A. Entropy Generation Minimization: The Method of Thermodynamic Optimization of Finite-Size Systems and Finite-Time Processes; Mechanical and Aerospace Engineering Series; Taylor \& Francis: Boca Raton, FL, USA, 1995; ISBN 978-0-84939-651-9.

23. Ying, Y.; Hu, E.J. Thermodynamic advantages of using solar energy in the regenerative Rankine power plant. Appl. Therm. Eng. 1999, 19, 1173-1180. [CrossRef]

24. Moran, M.J.; Shapiro, H.N.; Boettner, D.D.; Bailey, M.B. Fundamentals of Engineering Thermodynamics, 8th ed.; Wiley: Hobooken, NJ, USA, 2014; ISBN 978-1-118-41293-0.

25. Balmer, R.T. Modern Engineering Thermodynamics, 1st ed.; Academic Press: Cambridge, MA, USA, 2011; ISBN 008-096-1738.

26. Siemens. Efficiency Turns Less into More; Siemens: Munich, Germany, 2017.

27. Coco-Enríquez, L.; Muñoz-Antón, J.; Martínez-Val, J.M. Innovations on direct steam generation in linear Fresnel collectors. In Proceedings of the SolarPACES2013, Las Vegas, NV, USA, 17-20 September 2013; p. 45721.

28. Bejan, A. Advanced Engineering Thermodynamics, 1st ed.; Wiley: Hoboken, NJ, USA, 2016; ISBN 978-0-47090-037-6.

29. Bartlett, R.L. Steam Turbine Performance and Economics, 1st ed.; McGraw-Hill: New York, NY, USA, 1958.

30. Tabatabaian, M.; Post, S.; Rajput, R.K. Advanced Thermodynamics; Mercury Learning Series; Mercury Learning \& Information: Herndon, VA, USA, 2017; ISBN 978-1-93642-027-8.

31. Boito, P.; Grena, R. Optimization of the geometry of Fresnel linear collectors. Sol. Energy 2016, 135, 479-486. [CrossRef]

32. Veynandt, F. Cogénération Héliothermodynamique avec Concentrateur Linéaire de Fresnel: Modélisation de L'ensemble du Procédé. Ph.D. Thesis, Université de Toulouse, Toulouse, France, 2011.

33. González-Mora, E.; Durán García, M.D. Energy and Exergy (2E) Analysis of an Optimized Linear Fresnel Reflector for a Conceptual Direct Steam Generation Power Plant. In Proceedings of the ISES Solar World Congress 2019, Santiago, Chile, 4-7 November 2019; International Solar Energy Society: Freiburg, Germany, 2019; pp. 907-918.

34. Özışık, M.N. Radiative Transfer and Interactions with Conduction and Convection, 1st ed.; Wiley: Hoboken, NJ, USA, 1973; ISBN 978-0-47165-722-4.

35. Howell, J.R.; Menguc, M.P.; Siegel, R. Thermal Radiation Heat Transfer, 6th ed.; CRC Press: Boca Raton, FL, USA, 2015; Volume 92, ISBN 978-1-49875-774-4.

36. Rabl, A. Active Solar Collectors and Their Applications; Oxford University Press: Oxford, UK, 1985; ISBN 978-0-19536-521-4.

37. Raithby, G.D.; Hollands, K.G.T. A General Method of Obtaining Approximate Solutions to Laminar and Turbulent Free Convection Problems. Adv. Heat Transf. 1975, 11, 265-315.

38. Churchill, S.W.; Chu, H.H.S. Correlating equations for laminar and turbulent free convection from a horizontal cylinder. Int. J. Heat Mass Transf. 1975, 18, 1049-1053. [CrossRef]

39. Churchill, S.W.; Bernstein, M. A Correlating Equation for Forced Convection From Gases and Liquids to a Circular Cylinder in Crossflow. J. Heat Transf. 1977, 99, 300-306. [CrossRef]

40. Žukauskas, A. Heat Transfer from Tubes in Crossflow. Adv. Heat Transf. 1972, 8, 93-160.

41. Pohlhausen, E. Der Wärmeaustausch zwischen festen Körpern und Flüssigkeiten mit kleiner reibung und kleiner Wärmeleitung. ZAMM J. Appl. Math. Mech. Z. Angew. Math. Mech. 1921, 1, 115-121. [CrossRef]

42. Bergman, T.L.; Lavine, A.S.; Incropera, F.P.; Dewitt, D.P. Fundamentals of Heat and Mass Transfer, 7th ed.; John Wiley \& Sons, Inc.: Hoboken, NJ, USA, 2011; ISBN 978-0-47050-197-9.

43. Gungor, K.E.; Winterton, R.H.S. A general correlation for flow boiling in tubes and annuli. Int. J. Heat Mass Transf. 1986, 29, 351-358. [CrossRef]

44. Forristall, R. Heat Transfer Analysis and Modeling of a Parabolic Trough Solar Receiver Implemented in Engineering Equation Solver; National Renewable Energy Lab.: Golden, CO, USA, 2003. 
45. Adiutori, E.F. A Critical Examination of Correlation Methodology Widely Used in Heat Transfer and Fluid Flow. In Proceedings of the ASME 2004 Heat Transfer/Fluids Engineering Summer Conference ASMEDC, Charlotte, NC, USA, 11-15 July 2004; Volume 1, pp. 929-934.

46. Adiutori, E.F. Why Conventional Engineering Science should be Abandoned, and the New Engineering Science that should Replace It. Am. J. Mech. Eng. 2020, 9, 1-6. [CrossRef]

47. Mertins, M. Technische und Wirtschaftliche Analyse von Horizontalen Fresnel-Kollektoren. Ph.D. Thesis, Universität Karlsruhe, Baden-Württemberg, Gremany, 2009.

48. Meteotest Meteonorm; Version 7.2; METEOTEST: Bern, Switzerland, 2018.

49. Wang, Z. Design of Solar Thermal Power Plants; Elsevier Science: Amsterdam, The Netherlands, 2019; ISBN 978-0-12815-613-1.

50. Lovegrove, K.; Stein, W. Chapter 1-Introduction to concentrating solar power technology. In Concentrating Solar Power Technology; Lovegrove, K., Stein, W.B.T.-C.S.P.T., Eds.; Woodhead Publishing Series in Energy; Woodhead Publishing: Cambridge, UK, 2021; pp. 3-17. ISBN 978-0-12-819970-1.

51. Parrott, J.E. Theoretical upper limit to the conversion efficiency of solar energy. Sol. Energy 1978, 21, $227-229$.

52. Bejan, A. Entropy Generation through Heat and Fluid Flow; Wiley: Hoboken, NJ, USA, 1982; Volume 1, ISBN 0-471-09438-2.

53. Paoletti, S.; Rispoli, F.; Sciubba, E. Calculation of exergetic losses in compact heat exchanger passages. In Proceedings of the ASME AES, San Francisco, CA, USA, 10-15 December 1989; Volume 10, pp. 21-29.

54. Blanco, M.J.; Miller, S. 1-Introduction to concentrating solar thermal (CST) technologies. In Advances in Concentrating Solar Thermal Research and Technology; Elsevier: Amsterdam, The Netherlands, 2017; pp. 3-25. 